\title{
Comparison of the measured and modelled electron densities and temperatures in the ionosphere and plasmasphere during 20-30 January, 1993
}

\author{
A. V. Pavlovi,2, T. Abe ${ }^{2}$, K.-I. Oyama ${ }^{2}$ \\ ${ }^{1}$ Institute of Terrestrial Magnetism, Ionosphere and Radio-Wave Propagation, Russia Academy of Science (IZMIRAN), \\ Troitsk, Moscow Region, 142190, Russia \\ ${ }^{2}$ Institute of Space and Astronautical Science (ISAS), 3-1-1 Yoshinodai, Sagamihara, Kanagawa, 229-8510, Japan
}

Received: 6 December 1999 / Revised: 10 April 2000 / Accepted: 16 May 2000

\begin{abstract}
We present a comparison of the electron density and temperature behaviour in the ionosphere and plasmasphere measured by the Millstone Hill incoherent-scatter radar and the instruments on board of the EXOS-D satellite with numerical model calculations from a time-dependent mathematical model of the Earth's ionosphere and plasmasphere during the geomagnetically quiet and storm period on 20-30 January, 1993. We have evaluated the value of the additional heating rate that should be added to the normal photoelectron heating in the electron energy equation in the daytime plasmasphere region above $5000 \mathrm{~km}$ along the magnetic field line to explain the high electron temperature measured by the instruments on board of the EXOS-D satellite within the Millstone Hill magnetic field flux tube in the Northern Hemisphere. The additional heating brings the measured and modelled electron temperatures into agreement in the plasmasphere and into very large disagreement in the ionosphere if the classical electron heat flux along magnetic field line is used in the model. A new approach, based on a new effective electron thermal conductivity coefficient along the magnetic field line, is presented to model the electron temperature in the ionosphere and plasmasphere. This new approach leads to a heat flux which is less than that given by the classical Spitzer-Harm theory. The evaluated additional heating of electrons in the plasmasphere and the decrease of the thermal conductivity in the topside ionosphere and the greater part of the plasmasphere found for the first time here allow the model to accurately reproduce the electron temperatures observed by the instruments on board the EXOS-D satellite in the plasmasphere and the Millstone Hill incoherent-scatter radar in the ionosphere. The effects of the daytime additional plasmaspheric heating of electrons on the electron temperature and density are small at the F-region altitudes if the modified electron heat flux is
\end{abstract}

Correspondence to: A. V. Pavlov

e-mail: pavlov@izmiran.rssi.ru used. The deviations from the Boltzmann distribution for the first five vibrational levels of $\mathrm{N}_{2}(v)$ and $\mathrm{O}_{2}(v)$ were calculated. The present study suggests that these deviations are not significant at the first vibrational levels of $\mathrm{N}_{2}$ and $\mathrm{O}_{2}$ and the second level of $\mathrm{O}_{2}$, and the calculated distributions of $\mathrm{N}_{2}(v)$ and $\mathrm{O}_{2}(v)$ are highly non-Boltzmann at vibrational levels $v>2$. The resulting effect of $\mathrm{N}_{2}(v>0)$ and $\mathrm{O}_{2}(v>0)$ on $\mathrm{NmF} 2$ is the decrease of the calculated daytime $\mathrm{NmF} 2$ up to a factor of 1.5. The modelled electron temperature is very sensitive to the electron density, and this decrease in electron density results in the increase of the calculated daytime electron temperature up to about $580 \mathrm{~K}$ at the F2 peak altitude giving closer agreement between the measured and modelled electron temperatures. Both the daytime and night-time densities are not reproduced by the model without $\mathrm{N}_{2}(v>0)$ and $\mathrm{O}_{2}(v>0)$, and inclusion of vibrationally excited $\mathrm{N}_{2}$ and $\mathrm{O}_{2}$ brings the model and data into better agreement.

Key words: Ionosphere (ionospheric disturbances; ionosphere-magnetosphere interactions; plasma temperature and density)

\section{Introduction}

A particular solstice period between 20-30 January, 1993, represents a global "10 day campaign" period wherein many ionospheric, and thermospheric instruments collected data, and collaborative studies of the structure, dynamics and electron energy balance of the ionosphere were performed using the Millstone Hill and Arecibo incoherent scatter radar data and other groundbased data (Buonsanto et al., 1997; Fesen et al., 1997; Forbes et al., 1997; Richards and Khazanov, 1997; Scali et al., 1997). During the 20-30 January, 1993, period the plasmaspheric electron temperature and density has also been measured routinely by the instruments on board the 
EXOS-D satellite. This satellite was launched in early 1989 and studies of the plasmasphere and its coupling with the ionosphere were performed by using EXOS-D data (Abe et al., 1993; Balan et al., 1996a, b; Denton et al., 1999). On the primary purpose is to report the results obtained from a study of the electron density and temperature variations in the ionosphere and plasmasphere carried out using the incoherent scatter radar data at Millstone Hill, the EXOS-D satellite observations and the ionosphere-plasmasphere model. We study for the first time the electron density and temperature altitude profiles obtained from the measurements by the incoherent scatter radar in the ionosphere and by the EXOS$\mathrm{D}$ satellite in the plasmasphere.

The $\mathrm{O}^{+}\left({ }^{4} \mathrm{~S}\right)$ ions that predominate in the ionospheric $\mathrm{F} 2$-region are lost in the reactions

$\mathrm{O}^{+}\left({ }^{4} \mathrm{~S}\right)+\mathrm{N}_{2}(v) \rightarrow \mathrm{NO}^{+}+N$

$\mathrm{O}^{+}\left({ }^{4} \mathrm{~S}\right)+\mathrm{O}_{2}(v) \rightarrow \mathrm{O}_{2}^{+}+\mathrm{O}$

with the loss rate

$L=K\left[\mathrm{~N}_{2}\right]+\beta\left[\mathrm{O}_{2}\right]$,

where $v=0,1, \ldots$ is the number of the vibrational level of $\mathrm{N}_{2}$ or $\mathrm{O}_{2}$, the effective rate coefficients of reactions (1), and (2) are determined as

$K=\sum_{v=0}^{\infty}\left[\mathrm{N}_{2}(v)\right] K_{v} /\left[\mathrm{N}_{2}\right], \quad \beta=\sum_{v=0}^{\infty}\left[\mathrm{O}_{2}(v)\right] \beta_{v} /\left[\mathrm{O}_{2}\right]$,

$K_{v}$ is the recombination rate coefficient of $\mathrm{O}^{+}\left({ }^{4} \mathrm{~S}\right)$ ions with $\mathrm{N}_{2}(v), \beta_{v}$ is the recombination rate coefficient of $\mathrm{O}^{+}\left({ }^{4} \mathrm{~S}\right)$ ions with $\mathrm{O}_{2}(v),\left[\mathrm{N}_{2}\right]=\sum_{v=0}^{\infty}\left[\mathrm{N}_{2}(v)\right],\left[\mathrm{O}_{2}\right]=$ $\sum_{v=0}^{\infty}\left[\mathrm{O}_{2}(v)\right],\left[\mathrm{N}_{2}(v)\right]$ and $\left[\mathrm{O}_{2}(v)\right]$ are the number densities of $\mathrm{N}_{2}$ and $\mathrm{O}_{2}$ at the $v$-th vibrational level.

Schmeltekopf et al. (1968) measured $K\left(T_{\mathrm{N}_{2} v}\right)$ over the vibrational temperature range $300-6000 \mathrm{~K}$, and found the $K_{v} / K_{0}$ ratios from the measured $K\left(T_{\mathrm{N}_{2} v}\right)$ for $T_{n}=$ $T_{i}=300 \mathrm{~K}$ where $T_{\mathrm{N}_{2} v}$ is the vibrational temperature of $\mathrm{N}_{2}, T_{n}$ is the neutral temperature, and $T_{i}$ is the ion temperature. The fundamental results of Schmeltekopf et al. (1968) were confirmed by Ferguson et al. (1984). The measurements of $K$ were given by Hierl et al. (1997) over the temperature range $300-1600 \mathrm{~K}$ for $T_{n}=T_{i}=$ $T_{\mathrm{N}_{2} v}$. These results confirm the observations of Schmeltekopf et al. (1968), and show for the first time that the translation temperature dependencies of $K_{v}$ is similar to $K_{0}$. We examine the effects of $\mathrm{N}_{2}(v)$ on the electron density and temperature during 20-30 January, 1993, by using the $K_{v} / K_{0}$ ratios given by Hierl et al. (1997), and the value of $K_{0}$ measured by Albritton et al. (1977).

Hierl et al. (1997) found a big difference between the high-temperature flowing afterglow and drift tube measurements (McFarland et al., 1973; Albritton et al. 1977) of $\beta$ as a result of the input of the reactions between the vibrationally excited $\mathrm{O}_{2}$ and $\mathrm{O}^{+}\left({ }^{4} \mathrm{~S}\right)$, and determined the dependence of $\beta$ on the $\mathrm{O}_{2}$ vibrational temperature, $T_{\mathrm{O}_{2} v}$, over the temperature range 300-1800 for $T_{\mathrm{O}_{2} v}=T_{n}=T_{i}$. The flowing afterglow measurements of $\beta$ given by Hierl et al. (1997) were used by Pavlov (1998b) to invert the data to give the rate coefficients $\beta_{v}$ for the various vibrational levels of $\mathrm{O}_{2}(v>0)$ for the model of the Boltzmann distribution of vibrationally excited molecular oxygen. The difference between the measurements of $\beta$ given by Hierl et al. (1997) and the scaled drift tube data is decreased with the decrease in $T_{n}$. As a result, like $\mathrm{N}_{2}(v)$, the effects of the vibrational excitation of $\mathrm{O}_{2}$ are expected to be more important during solar maximum than at solar minimum. First studies of the $\mathrm{O}_{2}(v>0)$ effects on the $\mathrm{F} 2$ peak density, NmF2, for the 6-12 April 1990 storm (Pavlov, 1998b) and the 5-11 June, 1991, storm (Pavlov et al., 1999) found that enhanced vibrational excitation of $\mathrm{O}_{2}$ leads up to the $40 \%$ decrease in the calculated $\mathrm{NmF} 2$ at solar maximum. In this paper we study the effects of $\mathrm{O}_{2}(v>0)$ on the electron density and temperature for the period of 20-30 January, 1993, which was at moderate solar-activity conditions.

High electron temperatures in the night-time ionosphere over Millstone Hill were observed during the periods 20-30 January 1993 (Buonsanto et al., 1997; Richards and Khazanov, 1997). Such anomalous nighttime electron temperature events over Millstone Hill that were first observed in 1964 by Evans (1967) are most frequent in the winter months (Garner et al., 1994). The physical origin of these temperature events is still unclear. The Millstone Hill's conjugate point is sunlit the whole night for the most of the winter period, but the night-time electron temperature enhancements only occur for a few hours. The existence of anomalous night-time temperature events in the fall and spring months also does not support the idea of Evans (1967) that the heating is only caused by a simple relationship of these anomalous temperature enhancements to conjugate photoelectrons (Garner et al., 1994). Richards and Khazanov (1997) found that the plasmaspheric heating from photoelectrons must be doubled to reproduce the Millstone Hill observed topside electron temperature by the FLIP model of the ionosphere and plasmasphere during the periods 25-29 January 1993. Following Richards and Khazanov (1997), we believe that there is an additional heating rate of the electrons in the plasmasphere, and evaluate the value of this additional heating rate so that an agreement between the measured and modelled electron temperature in the ionosphere and plasmasphere is obtained during the 20-30 January, 1993, period.

The thermal electron impact excitation of the fine structure levels of the ${ }^{3} \mathrm{P}$ ground state of atomic oxygen is presently believed to be one of the dominant electron cooling processes in the $\mathrm{F}$ region of the ionosphere (Richards et al. 1986; Richards and Khazanov, 1997). Pavlov (1998a, c) and Pavlov and Berrington (1999) have revised and evaluated the electron cooling rates by vibrational and rotational excitation of $\mathrm{N}_{2}$ and $\mathrm{O}_{2}$, and the electron cooling rate by electron impact excitation of fine-structure levels of atomic oxygen. Pavlov and Berrington (1999) found that the role of the cooling rate of thermal electrons by electron impact excitation of fine structure levels of atomic oxygen is not significant at the F2-peak altitudes of the ionosphere for the geomagnetically quiet and disturbed period on 6-12 April, 1990, above Millstone Hill, and the energy exchange between 
the electron and ion gases and the electron cooling rates by vibrational excitation of $\mathrm{O}_{2}$ and $\mathrm{N}_{2}$ are the largest cooling rates above $160 \mathrm{~km}$. The new analytical expressions for cooling rates given by Pavlov (1998a, c) and Pavlov and Berrington (1999) are applied to study the thermal balance of the ionosphere and plasmasphere and to perform an examination of the role of these electron cooling rates in the thermal balance of the ionosphere during 20-30 January, 1993.

\section{Theoretical model}

The model used is the IZMIRAN model of the ionosphere and plasmasphere that has been steadily developed over the years (Pavlov, 1997, 1998a, b, c; Pavlov et al., 1999; Pavlov and Berrington, 1999). It is a one-dimensional model that uses a tilted dipole approximation to the Earth's magnetic field and takes into account the offset between the geographic and geomagnetic axes. In the model, coupled time-dependent equations of continuity and energy balance, and diffusion equations for electrons, and $\mathrm{O}^{+}\left({ }^{4} \mathrm{~S}\right), \mathrm{H}^{+}$, and $\mathrm{He}^{+}$ions are solved along a centred-dipole magnetic field line for the concentrations, temperatures, and field-aligned diffusion velocities of ions and electrons from a base altitude $(160 \mathrm{~km})$ in the Northern Hemisphere through the plasmasphere to the same base altitude in the Southern Hemisphere. Electron heating due to photoelectrons is provided by a solution of the Boltzmann equation for photoelectron flux. In the altitude range $120-700 \mathrm{~km}$ in the Northern and Southern Hemispheres the model solves time-dependent continuity equations for $\mathrm{O}^{+}\left({ }^{2} \mathrm{D}\right), \mathrm{O}^{+}\left({ }^{2} \mathrm{P}\right), \mathrm{NO}^{+}, \mathrm{O}_{2}^{+}, \mathrm{N}_{2}^{+}, \mathrm{N}_{2}(v=1, \ldots .5)$, and $\mathrm{O}_{2}(v=1, \ldots 5)$, and vibrationally excited nitrogen and oxygen quanta. An additional production of $\mathrm{O}^{+}\left({ }^{4} \mathrm{~S}\right)$, $\mathrm{O}^{+}\left({ }^{2} \mathrm{D}\right)$, and $\mathrm{O}^{+}\left({ }^{2} \mathrm{P}\right)$ ions is that described by Pavlov (1998b), and obtained in the model by inclusion of $\mathrm{O}^{+}\left({ }^{4} \mathrm{P}\right)$ and $\mathrm{O}^{+}\left({ }^{2} \mathrm{P}^{*}\right)$ ions. The IZMIRAN model calculates $\left[\mathrm{O}\left({ }^{1} \mathrm{D}\right)\right]$ from a time dependent continuity equation in the region between 120 and $1500 \mathrm{~km}$ in altitude in both hemispheres. The diffusion of ions and excited species are taken into account in continuity equations for $\mathrm{NO}^{+}, \mathrm{O}_{2}^{+}, \mathrm{O}_{2}(v), \mathrm{N}_{2}(v)$, and $\mathrm{O}\left({ }^{1} \mathrm{D}\right)$, while densities of $\mathrm{O}^{+}\left({ }^{2} \mathrm{D}\right), \mathrm{O}^{+}\left({ }^{2} \mathrm{P}\right)$, and $\mathrm{N}_{2}^{+}$are obtained from local chemical equilibrium. The updated IZMIRAN model uses the dissociative recombination rate coefficient for $\mathrm{N}_{2}^{+}$ions measured by Peterson et al. (1998). The revised electron cooling rates by vibrational and rotational excitation of $\mathrm{O}_{2}$ and $\mathrm{N}_{2}$, and by electron impact excitation of fine structure levels of atomic oxygen given by Pavlov (1998a, c) and Pavlov and Berrington (1999) are included in the model. To calculate the density of NO the algorithm given by Titheridge (1997) is used.

The heating rate of the electron gas by photoelectrons is calculated along a centred - dipole magnetic field line using the numerical method of Krinberg and Tachilin (1984) for the determination of the photoelectron fluxes within a plasmaspheric field tube on the same field line grid that is used in solving for the temperatures. The updated IZMIRAN model solves the Boltz- mann equation for photoelectron flux using the updated elastic and inelastic cross sections of the neutral components of the atmosphere. For $\mathrm{O}$, the elastic cross section employed in the electron transport code was drawn from the work of Williams and Allen (1989) for energies below $8.7 \mathrm{eV}$, and, above $8.7 \mathrm{eV}$, we have adopted the elastic cross section of Joshipura and Patel (1993). The $\mathrm{N}_{2}$ elastic cross section of Itikawa (1994) for electron energies is used in our model. The $\mathrm{O}$ and $\mathrm{N}_{2}$ inelastic cross sections are given by Majeed and Strickland (1997), and we employ these cross sections with some modification for $\mathrm{N}_{2}$. The $\mathrm{N}_{2}$ vibrational excitation cross sections used by Majeed and Strickland (1997) in calculations of the $\mathrm{N}_{2}$ inelastic cross section were replaced by the $\mathrm{N}_{2}$ vibrational excitation cross sections of Robertson et al. (1997) for vibrational levels $v=1$ and 2 , and those of Schulz (1976) for $v=3-10$ with the normalization factor of 0.7 (see details in Pavlov, 1998 a). For $\mathrm{O}_{2}$, the elastic and inelastic cross sections are taken from Kanic et al. (1993).

The IZMIRAN model uses the recombination rate coefficient of $\mathrm{O}^{+}\left({ }^{4} \mathrm{~S}\right)$ ions with unexcited $\mathrm{N}_{2}(0)$ and $\mathrm{O}_{2}(0)$ (Albritton et al., 1977; St.-Maurice and Torr, $1978)$ and vibrationally excited $\mathrm{N}_{2}(v)$ and $\mathrm{O}_{2}(v)$ (Schmeltekopf et al., 1968; Hierl et al., 1997; Pavlov, 1998b) as described in detail by Pavlov (1998b) and Pavlov et al. (1999). The energy balance equations for ions of the IZMIRAN model take into account the perpendicular component, $E_{\perp}$, of the electric field with respect to the geomagnetic field and the rate coefficients of such important ionospheric processes as the reactions of $\mathrm{O}^{+}\left({ }^{4} \mathrm{~S}\right)$ with $\mathrm{N}_{2}$ and $\mathrm{O}_{2}$, and $\mathrm{N}_{2}^{+}$with $\mathrm{O}_{2}$ which depend on effective temperatures which are functions of the ion temperature, the neutral temperature and $E_{\perp}$ (Pavlov, 1997, 1998b). The measured value of $E_{\perp}$ can be used as an input parameter for our theoretical model.

To simulate magnetic storm effects on the neutral atmosphere the MSIS-86 model of Hedin (1987) was run using $3 \mathrm{~h} A p$ indices. The IZMIRAN model uses the solar EUV fluxes from the EUV97 model (Tobiska and Eparvier, 1998). At night our model includes the neutral ionization by scattered solar 121.6, 102.6 and $58.4 \mathrm{~nm}$ fluxes (Pavlov, 1997).

In the Northern Hemisphere instead of calculating thermospheric wind components by solving the momentum equations, the IZMIRAN model calculates an equivalent neutral wind from the F2 peak altitude, hmF2, measurements using the modified method of Richards (1991) described by Pavlov and Buonsanto (1997). For the Southern Hemisphere where we do not have observed hmF2 momentum equations for the horizontal components of the thermospheric wind are calculated in the altitude range $120-700 \mathrm{~km}$ to derive an equivalent plasma drift velocity, as described by Pavlov (1997).

\section{Solar-geophysical conditions and data}

The period of 20-30 January, 1993, was a period of moderate solar-activity conditions when the F10.7 solar 
activity index ranged from 100 to 110 , while the 81-day averaged F10.7 solar activity index was about 130 . The day of 20 January 1993 was geomagnetically disturbed when 3-h geomagnetic index $K p$ was between 1 and 4 . Most of the 21-24 and 27-28 January periods were geomagnetically quiet with $K p$ varying between 0 and 2 except for short time periods when $K p$ reached 3 . The maximum value of $K p$ was $5+$ during the minor geomagnetic storm of 25-26 January. $K p$ varied between 1 and 4 on 29 January and between 2 and 5 on 30 January.

The Millstone Hill incoherent scatter radar experiment ran from 12:32 UT on 20 January, 1993, to 00:04 UT on 31 January, 1993. The electron densities, electron and ion temperatures, and plasma line-of-sight velocities were measured using both the fixed zenithpointing $67-\mathrm{m}$ antenna and the fully steerable $46-\mathrm{m}$ antenna (for more details see Buonsanto et al., 1997). The ionospheric variations of the Millstone Hill incoherent scatter radar electron density, $N_{e}$, and temperature, $T_{e}$, used here were discussed in details by Buonsanto et al. (1997), Fesen et al. (1997), and Richards and Khazanov (1997).

The EXOS-D satellite experiments have provided new opportunities in recent years for investigating the plasmaspheric electron temperature and density and have increased our knowledge of the plasmasphere and its coupling with the ionosphere (Abe et al., 1990, 1993; Balan et al., 1996a, b; Denton et al., 1999). The EXOSD data obtained during 20-30 January, 1993, were analyzed to investigate the local time and altitude variations of electron density and temperature in the plasmasphere. The plasmaspheric measured electron temperature and density from the EXOS D satellite at the Millstone Hill latitude and longitude were selected within a field tube such that the magnetic latitude and longitude of the central magnetic field line of this field tube coincided with the Millstone Hill magnetic latitude and longitude. The distance, $R_{B}$, (in the direction perpendicular to magnetic field lines) between the surface field lines and the central field line of this field tube is taken so that this distance was minimized, and the number of measurements was large enough to compare the data with the model results. As a result, the EXOS-D satellite data between 15:24:15 UT and 15:25:59 UT on 22 January with $R_{B}=3.5^{\circ}$, and from 14:32:14 UT to $14: 36: 06$ UT on 24 January with $R_{B}=2^{\circ}$ fell within the Millstone Hill magnetic field flux tube in the Northern Hemisphere during the 20-30 January period and are used in our work.

It is well known that the electron temperature within the plasmasphere and topside ionosphere is anisotropic with respect to the geomagnetic field (Clark et al., 1973; Oyama and Schlegel, 1988; Denmark and Schunk, 1987; Khazanov et al., 1996). An instrument on board the EXOS-D satellite for measuring the temperature distribution of thermal electrons with respect to the geomagnetic field was installed on the tip of the satellite's solar cell paddles perpendicular to the satellite spin axis (more detailed information about the electron temperature measurements is given by Abe et al., 1990). It follows from our analysis of the EXOS-D data sets at middle latitudes that the ratio of the parallel temperature (along the geomagnetic field) of thermal electrons to the electron temperature in the direction perpendicular to the geomagnetic field is ranging from 1 to $1.2-1.3$ (see also Abe et al., 1990). During the time periods studied between 15:24:15 UT and 15:25:59 UT on 22 January, and from 14:32:14 UT to 14:36:06 UT on 24 January, the instrument observed the electron temperature within the Millstone Hill magnetic field flux tube in the direction of $60-90^{\circ}$ between the normal direction of the sensor plane and the direction of the geomagnetic field measuring a mixture of the parallel and perpendicular temperatures. The electron temperature estimation made for the events described includes the error of 15 $20 \%$, which is almost comparable to the largest case of the ratio of the parallel temperature to the perpendicular temperature. As a result, we do not discriminate between the parallel and perpendicular temperatures of thermal electrons in this study.

\section{Analysis and discussion}

\subsection{Altitude profiles of the measured and modelled electron density and temperature in the ionosphere and plasmasphere}

Figures 1 and 2 show altitude profiles of the measured (crosses) and modelled (lines) electron densities (left panels), and electron (middle panels) and ion (right panels) temperatures above Millstone Hill at 10:05 LT (15:04 UT) on 22 January, 1993, and 9:24 LT (14:23 UT) on 24 January, 1993. Dotted lines show the modelled results without an additional electron heating in the plasmasphere using the electron thermal conductivity coefficient, $K_{e}^{0}$, along the magnetic field line in the electron energy balance equation of the IZMIRAN model given by Pavlov (1996). The model results shown by solid and dashed lines in Figs. 1 and 2 will be discussed later. It should be noted that the agreement between the measured $N_{e}, T_{e}$ and $T_{i}$ (crosses), and the modelled $N_{e}, T_{e}$, and $T_{i}$ shown by solid lines is good except for high altitudes (above about $350 \mathrm{~km}$ ) at left panel of Fig. 1 where the measured electron density is higher than the calculated electron density.

Left and middle panels of Figs. 3 and 4 show the electron densities and temperatures measured by the EXOS-D satellite between 15:22:39 UT and 15:26:39 UT on 22 January and from 14:32:14 UT to 14:39:02 UT on 24 January within the Millstone Hill magnetic field flux tube with $R_{B}=3.5^{\circ}$ (crosses), and the electron density and temperature altitude profiles calculated by the IZMIRAN model along the central magnetic field line of this field tube (lines) at 10:05 LT (15:04 UT) on 22 January 1993 and 9:24 LT (14:23 UT) on 24 January, 1993.

Dotted lines in Figs. 3 and 4 show the modelled results without an additional electron heating in the plasmasphere using the electron thermal conductivity coefficient $K_{e}^{0}$ along the magnetic field line in the 


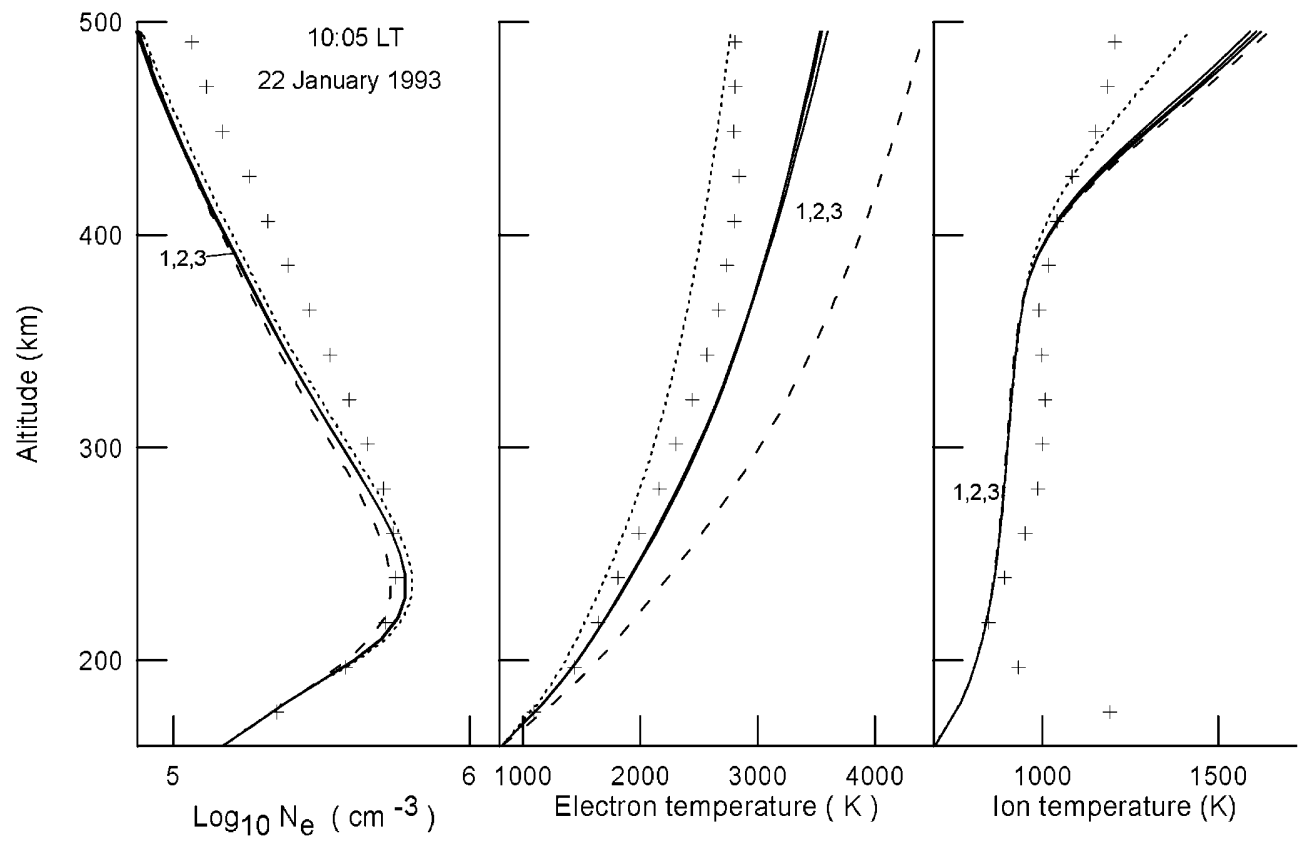

Fig. 1. Altitude profiles of the measured (crosses) and modelled (line) electron densities (left panel), electron temperatures (middle panel), and ion temperatures (right panel) above Millstone Hill at 10:05 LT (15:04 UT) on 22 January, 1993. The modelled results were obtained without an additional electron heating in the plasmasphere (dotted lines), and when the model includes the additional heating rate of the electron gas in the plasmasphere given by Eqs. (5), (6) when the value of $Q_{\text {day }}=1.4 \mathrm{eV} \mathrm{cm}^{-3} \mathrm{~s}^{-1}$ (dashed lines) and $Q_{\text {day }}=0.45 \mathrm{eV} \mathrm{cm}^{-3} \mathrm{~s}^{-1}$ (solid lines). Dotted and dashed lines show the results from the model using the electron thermal conductivity coefficient $K_{e}^{0}$ along the magnetic field line in the multicomponent mixture of ionised gases given by Pavlov (1996). Solid lines 1, 2, and 3 show the results from the model using the modified electron thermal conductivity coefficient along the magnetic field line given by Eq. (10) with the value of $C=10,20$ and 30 , correspondingly

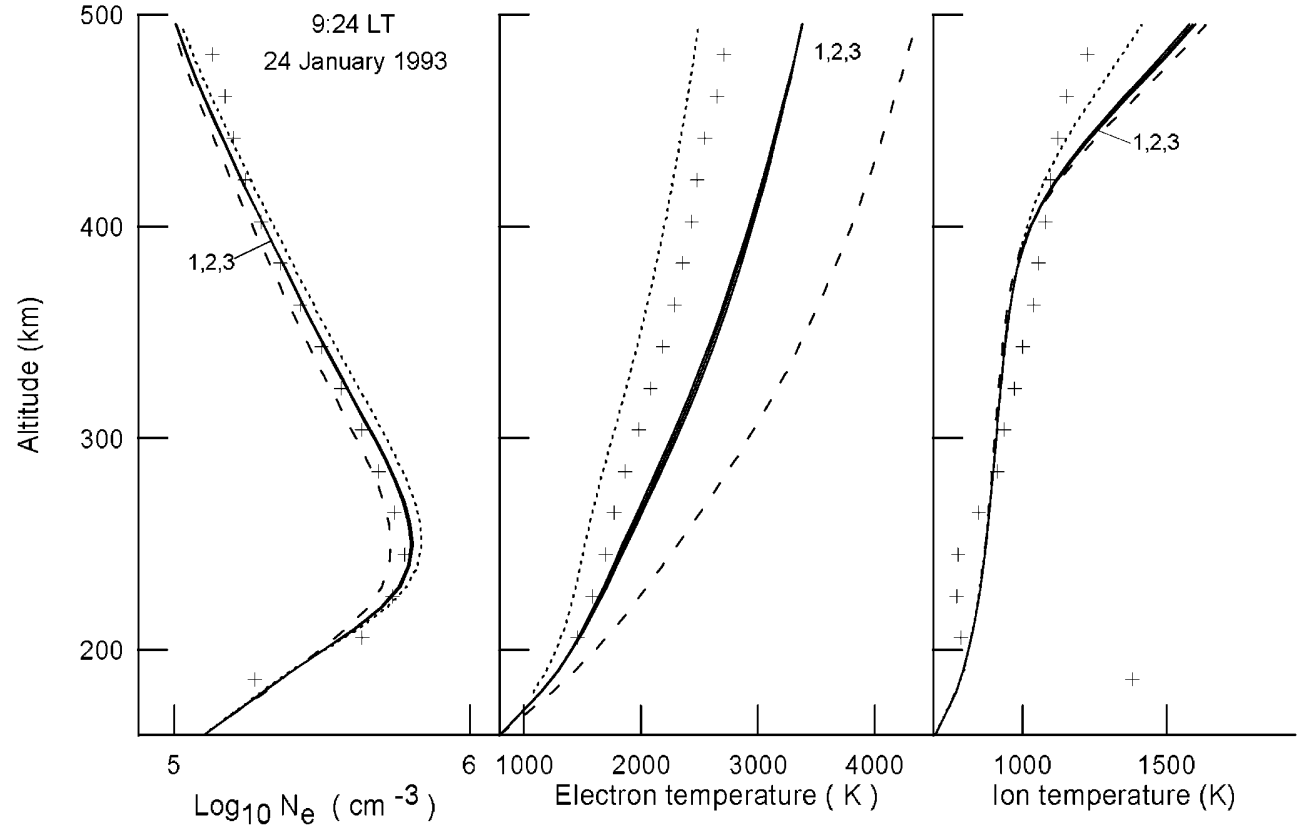

Fig. 2. Altitude profiles of the measured (crosses) and modelled (line) electron densities (left pan$e l$ ), electron temperatures (middle panel), and ion temperatures (right panel) above Millstone Hill at 9:24 LT (14:23 UT) on 24 January, 1993. The curves are the same as in Fig. 1 multicomponent mixture of ionised gases given by Pavlov (1996) which is used in the IZMIRAN model (Pavlov, 1997, 1998a, b, c; Pavlov et al., 1999; Pavlov and Berrington, 1999). In a completely ionised gas, the value of $K_{e}^{0}$ corresponds to the exact value calculated by Spitzer and Harm (1953) when an infinite number of terms were retained in Sonine expansion. As Figs. 3 and
4 show, the modelled electron temperatures shown by dotted lines are much less then the electron temperatures measured by the EXOS-D satellite in the plasmasphere.

The IZMIRAN model solves the Boltzmann equation for photoelectron flux along a centred-dipole magnetic field line to calculate the heating rate of the electron gas by photoelectrons using the numerical method of Krin- 

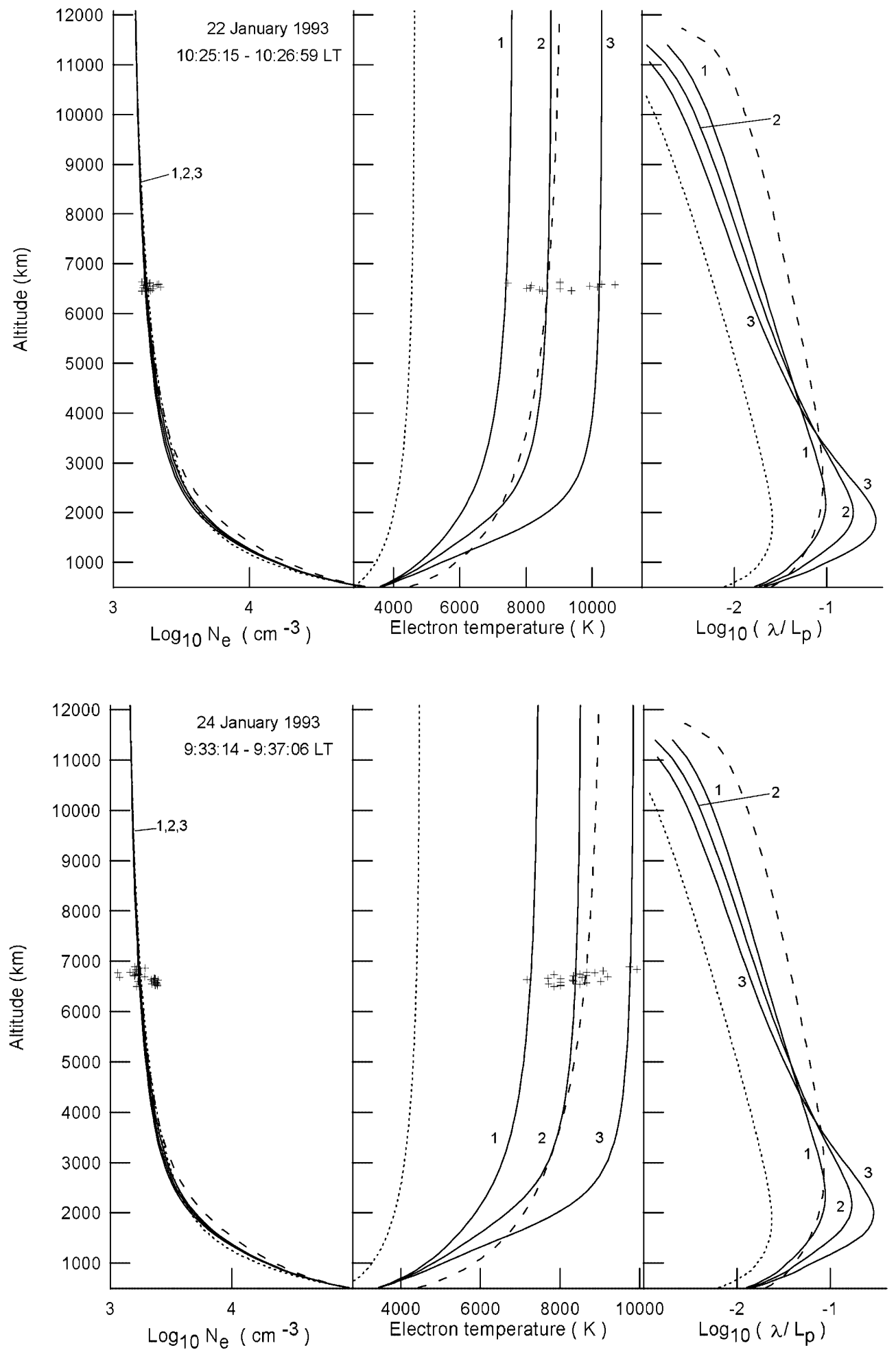

Fig. 3. The electron densities (left panel) and temperatures (middle panel) measured by the EXOS-D satellite between 10:25:15 LT (15:24:15 UT) and 10:26:59 LT (15:25:59 UT) on 22 January into the Millstone Hill magnetic field flux tube with $R_{B}=3.5^{\circ}$ (crosses), and calculated along the central magnetic field line of this field tube (lines) at 10:05 LT (15:04 UT) on 22 January, 1993. Right panel shows the calculated ratio of the thermal electron mean free path to the characteristic length of the electron temperature variation along the magnetic field line in the plasmasphere and ionosphere at 10:05 LT on 22 January, 1993. The curves are the same as in Fig. 1
Fig. 4. The electron densities (left panel) and temperatures (middle panel) measured by the EXOS-D satellite between 9:33:14 LT (14:32:14 UT) and 9:37:06 LT (14:36:06 UT) on 24 January into the Millstone Hill magnetic field flux tube with $R_{B}=2^{\circ}$ (crosses), and calculated along the central magnetic field line of this field tube (lines) at 9:24 LT (14:23 UT) on 24 January, 1993. Right panel shows the calculated ratio of the thermal electron mean free path to the characteristic length of the electron temperature variation along the magnetic field line in the plasmasphere and ionosphere at 9:24 LT on 24 January 1993. The curves are the same as in Fig. 1 berg and Tachilin (1984). The energy lost by photoelectrons in heating the plasma in the plasmasphere is calculated using the analytical equation for the plasmaspheric transparency, $P(E)$, (Krinberg and Matafonov, 1978; Krinberg and Tachilin, 1984) that determines the probability of the magnetically trapped photoelectrons with an energy, $E$, for entering the magnetically conjugated ionosphere. The transparency depends mainly on a single parameter proportional to the Coulomb cross section and the total content of electrons in the plasmasphere magnetic flux tube [the transparency approaches unity as photoelectrons pass through the plasmasphere without significant absorption, and $P(E)=0$ if photoelectrons are absorbed by the plasmasphere].

The disagreement between the measured (crosses) and modelled (dotted lines) electron temperatures shown in Figs. 1 and 2 could be due to uncertainties of the IZMIRAN model in the amount of the energy 
deposited in the plasmasphere by ionospheric photoelectrons. However, changing the value of $P(E)$ we have found that the heating provided by trapped photoelectrons cannot account for the observed high electron temperatures in the plasmasphere in Figs. 3 and 4.

The presence in the ionosphere and plasmasphere of photoelectrons is a potential source for the onset of plasma instabilities that can change the photoelectron distribution function and heating rate of electrons used by the IZMIRAN model. The possible additional sources of the electron gas heating in the plasmasphere, such as wave-particle interactions, which can cause increased photoelectron scattering, and Coulomb collisions between ring current ions and plasmaspheric electrons and ions could be the possible mechanisms to explain the observed electron temperature enhancements in the plasmasphere. It is also possible that the physics of ionosphere-plasmasphere transport of photoelectrons is not well understood at this time. The heating could be also caused by heated flux tubes drifting past Millstone Hill. It is worth noting that such required additional heat of electrons, over that for the usual photoelectron heating from Coulomb collisions, was used in many papers to make the modelled and measured electron temperatures agree (Horwitz et al., 1990; Pavlov, 1994, 1996, 1997; Graven et al., 1995; Balan et al., 1996b; Richards and Khazanov, 1997).

As a result, to explain the measured electron temperature we assume that an additional heating rate, $Q_{a d}$, should be added to the normal photoelectron heating in the electron energy equation in the plasmasphere region above $5000 \mathrm{~km}$ along the magnetic field line as

$Q_{a d}=Q_{d a y} \quad$ for $\chi \leq 90^{\circ}$,

$Q_{a d}=Q_{\text {night }}$ for $\chi>90^{\circ}$,

where $\chi$ is the solar zenith angle at the Earth's surface at Millstone Hill.

The value of $Q_{d a y}$ is found from the comparison between the electron temperatures observed by the instruments on board of the EXOS-D satellite in the plasmasphere and the calculated electron temperatures to allow the IZMIRAN model to accurately reproduce the measured electron temperatures. There is no nighttime EXOS-D electron temperature measurements into the Millstone Hill magnetic field flux tube during the 20 30 January period, and we cannot calculate the value of $Q_{\text {night }}$ from the comparison of the IZMIRAN model results and EXOS-D data. An algorithm presented in Sect. 4.2 for using the measured electron temperature at the F2 peak altitude to determine the amount of the IZMIRAN model night-time plasmaspheric additional heating is used in our calculations. We hope that the real mechanism of this additional heating will be found in future studies, and this study could only be considered as an adjusted approach to evaluate the value of this additional heating rate.

We found that good agreement between the measured and modelled electron temperatures in the plasmasphere is obtained if $Q_{\text {day }}=1.4 \mathrm{eV} \mathrm{cm}^{-3} \mathrm{~s}^{-1}$ (dashed lines in
Figs. 1-4). Comparison between crosses and dashed lines of Figs. 1 and 2 (middle panels) and Figs. 3 and 4 (middle panels) show that this additional heating brings the measured and modelled electron temperatures into agreement in the plasmasphere and into very large disagreement in the ionosphere. The following investigation seeks to resolve this striking discrepancy.

It is generally accepted that the Spitzer-Harm theory (Spitzer and Harm, 1953) of the electron thermal conductivity along the magnetic field line can be only applied for the highly collisional plasmas when the ratio of the thermal electron mean free path, $\lambda$, to the characteristic length, $L_{p}$, of the plasma parameter variation is less than about $10^{-2}$ (Bell et al., 1981; Khan and Rognlien, 1981; Mason, 1981; Matte and Virmont, 1982). The conventional thermal conductivity model of Spitzer and Harm (1953) may result in electron energy flux which is large and physically unreal (the classical electron conduction becomes infinite for collisionless plasma) and inconsistent with the results of weakly collisional plasma experiments (Choi and Wilhelm, 1976; Gray and Kilkenny, 1980; Gary et al., 1981; Clause and Balescu, 1982; Fechner and Mayer, 1984; Lee and More, 1984; Albritton et al., 1986). This is due to the fact that in these experiments the main contribution to the energy transport through the thermal conductivity comes from the suprathermal electrons whose mean free path is much larger than $\lambda$.

The question of how the electron heat flux, $q_{e}$, varies as $\lambda / L_{p}>10^{-2}$ is still, as yet, an unanswered question. One common, ad hoc approach is the flux-limited model given as (Malone et al., 1975; Cowie and Mckee, 1977; Fechner and Mayer, 1984)

$q_{e}=\left(q_{\text {clas }}^{-1}+q_{\text {sat }}^{-1}\right)^{-1}$,

where $q_{\text {clas }}=-K_{e}^{0}(\partial / \partial S) T_{e}$ is the classical electron heat flux along a magnetic field line, $S$ is the distance along the magnetic field line, $S$ is positive in the direction north to south.

The "saturated" electron heat flux in Eq. (7) is given by

$q_{s a t}=-f N_{e} k T_{e} V_{T}\left|\frac{\partial}{\partial S} T_{e}\right|^{-1} \frac{\partial}{\partial S} T_{e}$,

where $k$ is Boltzmann's coefficient, $V_{T}=\left(2 k T_{e} m_{e}^{-1}\right)^{0.5}$ is the electron thermal velocity, $m_{e}$ denotes the mass of an electron, and $f$ is a coefficient, known as the "flux limit" parameter (Malone et al., 1975; Cowie and Mckee, 1977; Fechner and Mayer, 1984).

It is explicitly indicated in Eq. (8) that the saturated heat flow is opposite to the temperature gradient. In the highly collisional limit, Eq. (7) reduces to the classical heat conduction equation, while in the weakly collisional limit, Eq. (7) describes the saturated heat flux of electrons.

The magnitude of the flux limit parameter is the subject of considerable discussions, and values of $f$ in two orders of the magnitude range from about 0.01 to about 1 in the literature. These values of $f$ are required to reproduce some laser fusion results with simulation 
code, and they have also been deduced in numerical Fokker-Planck calculations (Malone et al., 1975; Cowie and Mckee, 1977; Bell et al., 1981; Clause and Balescu, 1982; Matte and Virmont, 1982; Fechner and Mayer, 1984; Zawaideh and Kim, 1988).

Equation (7) can be modified as follows:

$q_{e}=-K_{e} \frac{\partial}{\partial S} T_{e}$,

where the effective electron thermal conductivity coefficient is determined as

$K_{e}=K_{e}^{0} /\left(1+C \lambda / L_{p}\right)$,

$C=1.6 f^{-1}, \quad L_{p}=T_{e}\left|\frac{\partial}{\partial S} T_{e}\right|^{-1}$.

Right panels of Figs. 3 and 4 show the calculated ratio altitude profiles of the thermal electron mean free path to the characteristic length of the electron temperature variation along the magnetic field line in the plasmasphere and ionosphere at 10:05 LT on 22 January, 1993, and 9:24 LT on 24 January, 1993. Dotted $\left(Q_{a d}=0\right)$ and dashed $\left(Q_{\text {day }}=1.4 \mathrm{eV} \mathrm{cm}^{-3} \mathrm{~s}^{-1}\right)$ lines represent the IZMIRAN model results when the classical electron heat flux along magnetic field line is used. Figures 3 and 4 show that the value of $\lambda / L_{p}$ is larger than $10^{-2}$ in the altitude region between $600-650 \mathrm{~km}$ and $5000-5200 \mathrm{~km}$ in the ionosphere and plasmasphere without an additional heating of electrons, and from $300-340 \mathrm{~km}$ to $10000-10500 \mathrm{~km}$ in the ionosphere and plasmasphere with the additional heating. It means that the additional heating rate of electrons increases the size of the region in the daytime ionosphere and plasmasphere where $\lambda / L_{p}$ is larger than $10^{-2}$. Application of the classical heat conduction equation to plasma in this region, that is not highly collisional, casts doubt on the accuracy of the results and creates the problem in agreement of the measured and modelled electron temperatures simultaneously in the daytime ionosphere and plasmasphere.

Solid lines in Figs. 1-4 represent the IZMIRAN model results when the additional heating $Q_{\text {day }}=$ $0.45 \mathrm{eV} \mathrm{cm}^{-3} \mathrm{~s}^{-1}$ and the modified electron heat flux along magnetic field line given by Eqs. (9), (10) with $C=10$ (solid lines 1 ), $C=20$ (solid lines 2), and $C=30$ (solid lines 3 ) are used. The right panels of Figs. 3 and 4 show that the value of $\lambda / L_{p}$ is larger than $10^{-2}$ in the altitude region between $400-450 \mathrm{~km}$ and $8500-8600 \mathrm{~km}$ for $C=10$, from $400-450 \mathrm{~km}$ to $7700-8000 \mathrm{~km}$ for $C=20$, and from $380-440 \mathrm{~km}$ to $7200-7400 \mathrm{~km}$ for $C=30$ in the ionosphere and plasmasphere. The maximum value of the $\lambda / L_{p}$ ratio is located in the plasmaspheric region between $1800 \mathrm{~km}$ and $2300 \mathrm{~km}$ if $C=10-30$. As a result of the reduced electron thermal conductivity, the modelled electron temperature is higher in the plasmasphere if the higher value of $C$ is used. The difference between electron temperatures given by solid lines 1,2 , and 3 is negligible below $500 \mathrm{~km}$. Our calculations show that this difference can be increased if the value of $Q_{d a y}$ is increased. It should be also noted that the effects of the additional plasmaspheric heating of electrons on the electron temperature and density are small at the F-region altitudes if the effective electron thermal conductivity coefficient given by Eq. (10) is used.

The Millstone Hill radar measurements of the topside electron temperature are difficult because of the low electron densities and a lot of scatter in the data. As a result, some difference between the measured and modelled topside electron temperatures may be due to the errors of the topside electron temperature measurements. The errors of the electron temperature measured by the instruments on board of the EXOS-D satellite can be evaluated as $15-20 \%$ while the errors in the EXOS-D electron density measurements are about factors of 2-3 at the considered altitudes. In general, we conclude that the modelled electron temperatures in the ionosphere and plasmasphere are in good agreement with the measurements if the new approach of Eqs. (9) and (10) for the electron heat flux along magnetic field line is used. Taking into account the errors of the electron temperature measurements we believe that the value of $C$ in Eq. (10) is between 10 and 30. The good agreement between the modelled and measured electron temperatures is achieved by using the middle value of $C=20$. The fitting approach of Eqs. (9) and (10) can be considered as the first step in the study of physical processes that are responsible for the high daytime plasmaspheric electron temperatures.

It should be noted that some models and simulations of anomalous transport processes have been presented for auroral plasma where the calculated $T_{e}$ based on classical transport coefficients disagrees strongly with the observed storm time $T_{e}$ in the auroral ionosphere below $500 \mathrm{~km}$ (Fontheim et al., 1978; Jonson et al., 1979). As a result of particle precipitation or electron current flow, plasma instabilities and turbulence are excited in the auroral ionosphere. The plasma turbulence leads to a decrease in electron thermal conductivity along the geomagnetic field and changes the thermal structure of the auroral ionosphere below $500 \mathrm{~km}$ giving an agreement between the measured and modelled electron temperatures (Fontheim et al., 1978; Jonson et al., 1979). Figures 3 and 4 show that the decrease in electron thermal conductivity is created in the fluxlimited model approach at middle latitudes above 500$700 \mathrm{~km}$ in the topside ionosphere and the plasmasphere to agree the measured and modelled electron temperature. However, as far as the authors know, the question about the plasma turbulence existence at middle latitudes above $500-700 \mathrm{~km}$ in the topside ionosphere and the plasmasphere has not been studied, and therefore this approach is not considered in our work.

\subsection{Additional heating of electrons in the plasmasphere from the comparison of the measured and modelled night-time electron temperatures at the F2 peak altitude}

The dependence of the electron temperature on the neutral densities and temperature, the electron density, and the heating rate of electron gas is determined by the energy balance equation for electrons (Pavlov, 1997, 
1998a, c; Pavlov and Berrington, 1999) with the electron heat flux along magnetic field line given by Eqs. (9), (10). Taking into account that an effect of cooling processes on the temperature of plasmasphere electrons is weak, we can integrate the steady state energy balance equation for electrons, with respect to $S$ from magnetic equator, $S=0$, to the distance, $X$, in the Northern Hemisphere along the field line, and obtain the following relation:

$$
\begin{aligned}
q_{e}(X)= & q_{e}(S=0)-B(X) \\
& \times \int_{X}^{0} B(S)^{-1}\left[Q_{a d}(S)+Q_{f o t}(S)\right] \mathrm{d} S,
\end{aligned}
$$

where $B$ is the magnitude of the geomagnetic field, $Q_{f o t}(S)$ is the heating rate of the electron gas by photoelectrons during night-time periods due to photoelectron flux from the sunlit conjugate hemisphere.

The value of the $\lambda / L_{p}$ ratio is proportional to $T_{e}\left|(\partial / \partial S) T_{e}\right|$. The mean night-time EXOS-D electron temperatures are less than the mean daytime EXOS-D electron temperatures in the plasmasphere (Abe et al., 1993; Balan et al., 1996a, b; Denton et al., 1999), and the night-time difference between $K_{e}$ and $K_{e}^{0}$ is less than the daytime difference. As a result, we can assume for an estimate that the dependence of $K_{e}$ on $T_{e}$ is close to the dependence of $K_{e}^{0}$ on $T_{e}$ at night. It means that at the upper boundary of the ionosphere the value of $T_{e}^{7 / 2}$ is approximately proportional to $Q_{a d}$. As there is no analytical solution of the steady state energy equation for electrons in the region of the ionosphere which takes into account the revised electron cooling rates of thermal electrons by electron impact excitation of fine structure levels of atomic oxygen and by vibrational and rotational excitation of $\mathrm{N}_{2}$ and $\mathrm{O}_{2}$ given by Pavlov (1998a, c) and Pavlov and Berrington (1999), we use Eq. (11) in the ionosphere to adjust the night-time model electron temperature. If the model electron temperature, $T_{\text {mod }}(t)$, at the time step, $t$, is less than the measured temperature, $T_{\exp }(t)$, the required heating rate at the next time step, $t+\Delta t$, is approximately given by

$Q_{a d}(t+\Delta t)=A\left[T_{m o d}^{7 / 2}-T_{e x p}^{7 / 2}\right]+Q_{a d}(t)$,

where $A$ is a constant.

Figures 5 and 6 show the measured (crosses) and calculated (lines) $\mathrm{NmF} 2$ (bottom panel), and $\mathrm{hmF} 2$ (middle panel) at the F2 peak altitude above Millstone

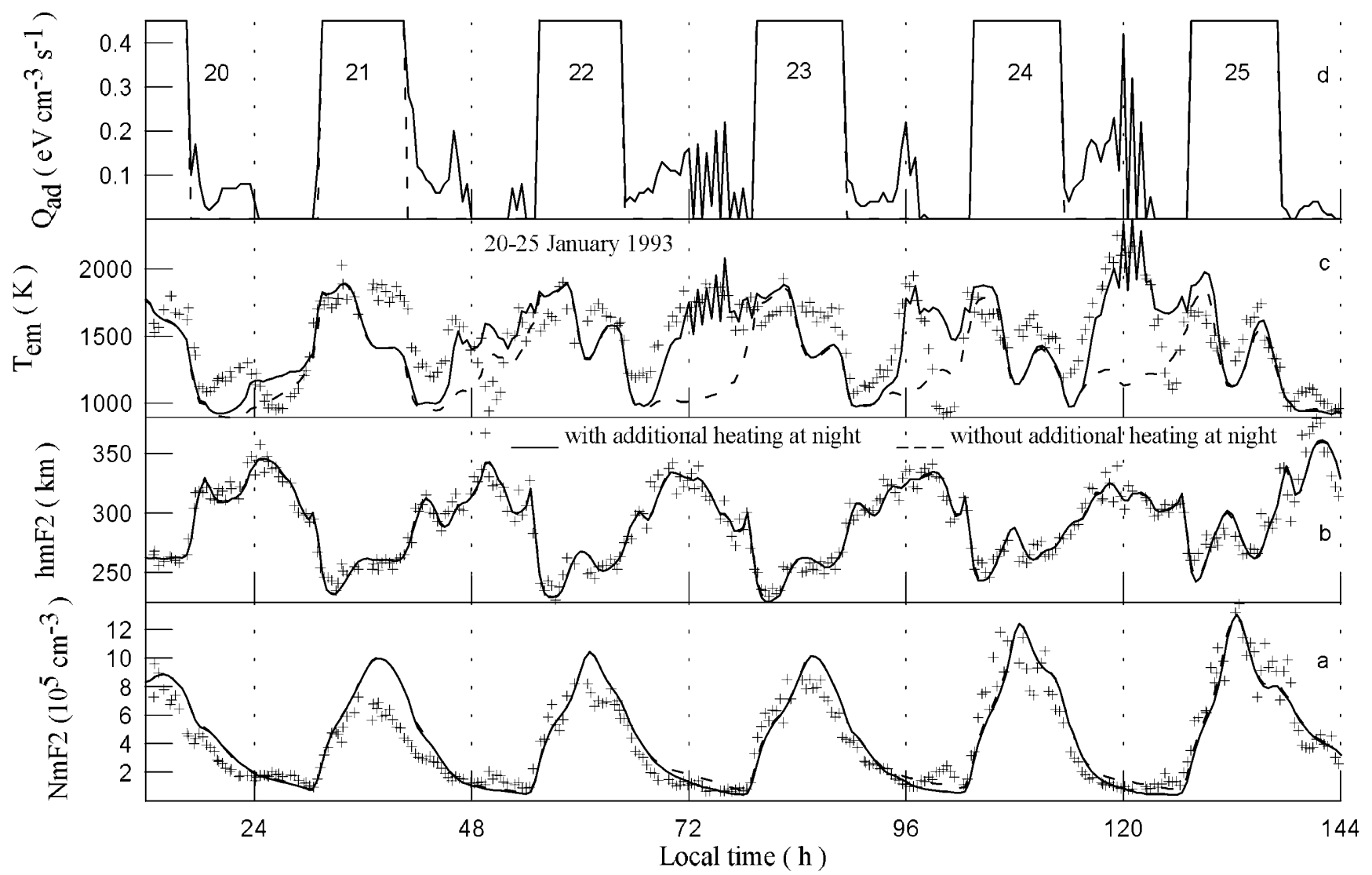

Fig. 5. Observed (crosses) and calculated (lines) NmF2 (bottom panel), and $\mathrm{hmF} 2$ (middle panel) at the $\mathrm{F} 2$ peak altitude above Millstone Hill for the magnetically quiet and disturbed period 20-25 January, 1993, for two models of additional heating of electrons in the plasmasphere (top panel). The model of the ionosphere and plasmasphere uses the modified electron thermal conductivity coefficient along the magnetic field line given by Eq. (10) with the value of $C=20$. Solid lines show the modelled results obtained when the approach of Eqs. (5) and (6) is used. Dashed lines represent the model results when the approach of Eq. (5) is used and $Q_{a d}=0$ for $\chi>90^{\circ}$ 


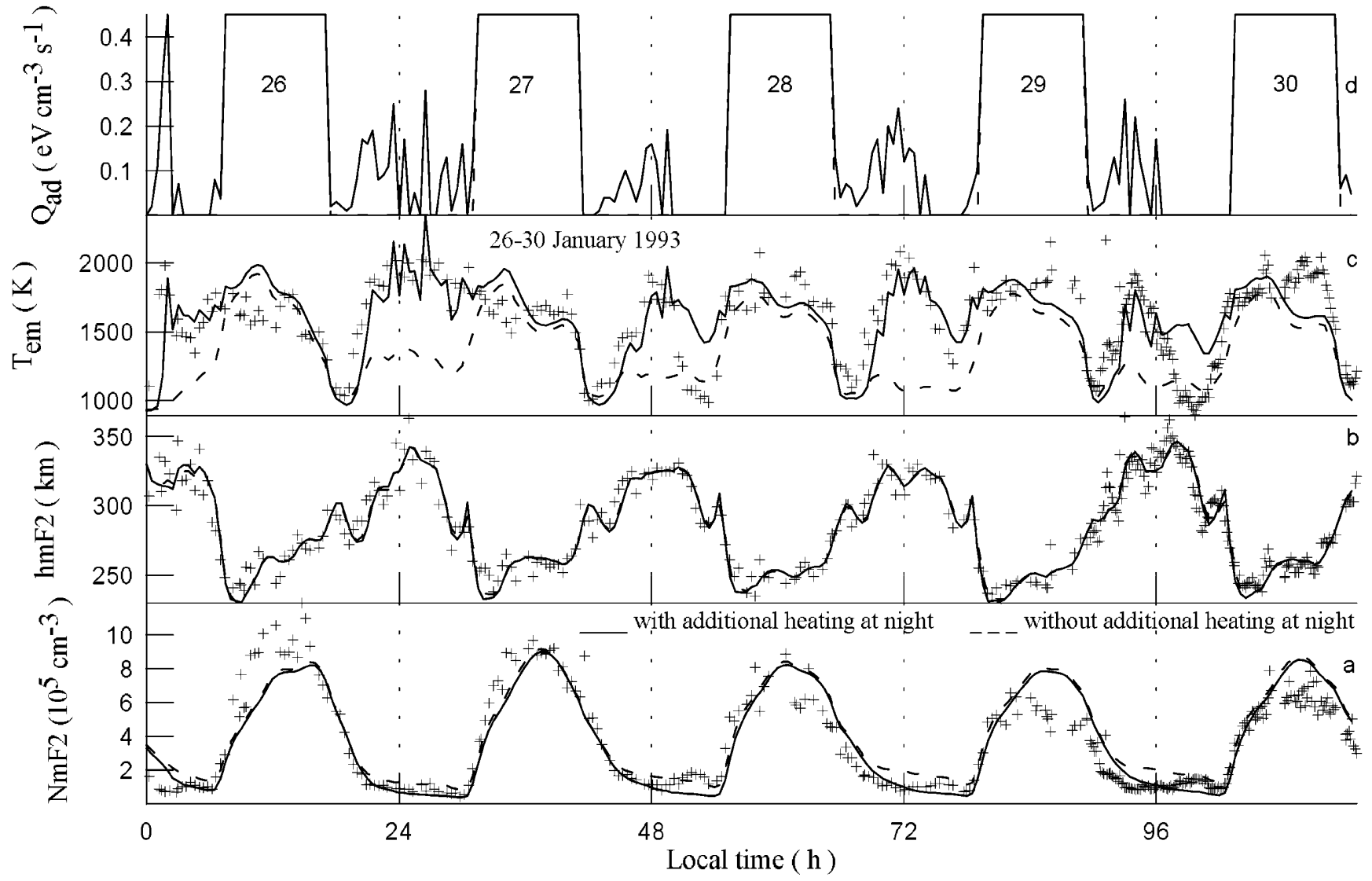

Fig. 6. Observed (crosses) and calculated (lines) NmF2 (bottom panel), and hmF2 (middle panel) at the F2 peak altitude above Millstone Hill for the magnetically quiet and disturbed period 26-30

Hill for the magnetically quiet and disturbed period of 20-30 January, 1993, for two models of additional heating of electrons in the plasmasphere (top panel). The modified electron thermal conductivity coefficient along the magnetic field line given by Eq. (10) with the value of $C=20$ used in the IZMIRAN model calculations. Solid lines show the modelled results obtained when the additional heating rate of electrons was specified using the algorithms given by Eqs. (5), (6), and (12). The approach of Eq. (12) uses the measured and modelled electron temperatures at the F2 peak altitude. Dashed lines represent the IZMIRAN model results when $Q_{a d}=0.45 \mathrm{eV} \mathrm{cm}^{-3} \mathrm{~s}^{-1}$ for $\chi \leq 90^{\circ}$ and $Q_{a d}=0$ for $\chi>90^{\circ}$ are used. The figures are divided into two parts to avoid a compressed time scale.

Dashed lines in the middle panel of Figs. 5 and 6 show that there is a difference at night with the model temperatures generally lower than the data. Solid lines in the middle panel of Figs. 5 and 6 show how well the IZMIRAN model electron temperature is able to follow the measured electron temperature using the algorithm of Eq. (12). We conclude that the model electron temperature is much closer to the measured electron temperature if the algorithm of Eq. (12) is used. Our results show that there are a number of peaks in additional heating time behaviour at night, and the value of $Q_{\text {night }}$ is less than $Q_{d a y}$. We found that
January, 1993, for two models of additional heating of electrons in the plasmasphere (top panel). The curves are the same as in Fig. 5

the effect of the calculated night-time additional heating (given by Eq. 6) on $\mathrm{NmF} 2$ can be considered negligible.

The accuracy of the calculated night-time additional heating depends on the accuracy of the modelled nighttime photoelectron flux from the sunlit conjugate hemisphere. Uncertainties in the theoretical solar EUV fluxes and in the measured electron impact cross sections can create up to about a factor of 2 uncertainties in the theoretical photoelectron spectra (Richards and Torr, 1988). Our calculations indicate that a factor of 2 increase in the photoelectron flux from the sunlit conjugate hemisphere leads to a decrease up to about a factor of 2 of the night-time additional heating if $Q_{\text {night }}>0.01 \mathrm{eV} \mathrm{cm}^{-3} \mathrm{~s}^{-1}$. However, a factor of 2 increase in the theoretical solar EUV fluxes that can produce a factor of 2 increase in the photoelectron flux leads to the disagreement between the measured and modelled electron densities in the ionosphere during the daytime periods of 20-30 January, 1993. Additional argument against this increase is that an increase up to about a factor of 2 of the photoelectron flux from the sunlit conjugate hemisphere cannot produce the agreement between the measured and modelled electron temperatures during all night-time periods of 20-30 January, 1993, and we believe that an additional heating of electrons exists in the plasmasphere. 


\subsection{Effects of vibrational excited oxygen and nitrogen on electron density and temperature of the ionosphere}

The full model of the ionosphere and plasmasphere solves time dependent continuity equations for number densities $\mathrm{N}_{2}(v=1, \ldots .5)$ and $\mathrm{O}_{2}(v=1, \ldots .5)$, and calculates deviations of $\left[\mathrm{N}_{2}(v)\right]$ and $\left[\mathrm{O}_{2}(v)\right]$ from the Boltzmann distribution of vibrationally excited molecular nitrogen $\left[\mathrm{N}_{2}(v)\right]_{B}=\left[\mathrm{N}_{2}(0)\right] \exp \left(-v E_{1} T_{\mathrm{N}_{2} v}^{-1}\right)$ and oxygen $\left[\mathrm{O}_{2}(v)\right]_{B}=$ $\left[\mathrm{O}_{2}(0)\right] \exp \left(-v E_{1}^{\prime} T_{\mathrm{O}_{2} v}^{-1}\right)$, where $E_{1}=3353 \mathrm{~K}$ and $E_{1}^{\prime}=$ $2239 \mathrm{~K}$ are the energies of the first vibrational levels of $\mathrm{N}_{2}$ and $\mathrm{O}_{2}\left(\right.$ Radzig and Smirnov, 1980), $\left[\mathrm{N}_{2}(0)\right]=\left[\mathrm{N}_{2}\right]$ $\left\{1-\exp \left(-E_{1} T_{\mathrm{N}_{2} v}^{-1}\right)\right\},\left[\mathrm{O}_{2}(0)\right]=\left[\mathrm{O}_{2}\right]\left\{1-\exp \left(-E_{1}^{\prime} T_{\mathrm{O}_{2} v}^{-1}\right)\right\}$, the vibrational temperatures are calculated by solving the time dependent continuity equations for vibrationally excited nitrogen and oxygen quanta (Pavlov, 1997, 1998b).

From the diurnal variations of the calculated vibrational and neutral temperatures shown in Fig. 7 it follows that $T_{\mathrm{O}_{2} v}<T_{n}$ and $T_{\mathrm{N}_{2} v}<T_{n}$ are realized in the atmosphere for some parts of the night-time periods where the production frequencies of $\mathrm{O}_{2}(v)$ and $\mathrm{N}_{2}(v)$ are low. This means that for these periods the populations of $\mathrm{O}_{2}(v)$ or $\mathrm{N}_{2}(v)$ are less than the populations for a Boltzmann distribution with temperature $T_{n}$. During daytime $T_{\mathrm{O}_{2} v}$ and $T_{\mathrm{N}_{2} v}$ are larger than $T_{n}$ due to the enhanced thermal excitation of $\mathrm{O}_{2}$ and $\mathrm{N}_{2}$ as a result of high thermal electron temperatures at $\mathrm{F} 2$ - region altitudes. We found that $-41 \mathrm{~K} \leq T_{\mathrm{O}_{2} v}-T_{n} \leq 373 \mathrm{~K}$ and $-63 \mathrm{~K} \leq T_{\mathrm{N}_{2} v}-T_{n} \leq 312 \mathrm{~K}$. The value of the vibrational temperature was not more than $1293 \mathrm{~K}$ for $\mathrm{O}_{2}$ and $1272 \mathrm{~K}$ for $\mathrm{N}_{2}$.

The present study suggests that the deviations of $\left[\mathrm{N}_{2}(v)\right]$ and $\left[\mathrm{O}_{2}(v)\right]$ from the Boltzmann distributions are not significant at the first vibrational levels of $\mathrm{N}_{2}$ and $\mathrm{O}_{2}$ and the second level of $\mathrm{O}_{2}:\left[\mathrm{N}_{2}(1)\right] /\left[\mathrm{N}_{2}(1)\right]_{B}=0.83-1.07$, $\left[\mathrm{O}_{2}(1)\right] /\left[\mathrm{O}_{2}(1)\right]_{B}=0.99-1.11,\left[\mathrm{O}_{2}(2)\right] /\left[\mathrm{O}_{2}(2)\right]_{B}=0.85-1.00$. The calculated distributions of $\mathrm{N}_{2}(v>1)$ and $\mathrm{O}_{2}(v>2)$ are highly non-Boltzmann: $\left[\mathrm{N}_{2}(2)\right] /\left[\mathrm{N}_{2}(2)\right]_{B}=0.89-2.86$, $\left[\mathrm{N}_{2}(3)\right] /\left[\mathrm{N}_{2}(3)\right]_{B}=1.7-72,\left[\mathrm{~N}_{2}(4)\right] /\left[\mathrm{N}_{2}(4)\right]_{B}=7.3-1260$, $\left[\mathrm{N}_{2}(5)\right] /\left[\mathrm{N}_{2}(5)\right]_{B}=45-1.1 \cdot 10^{5},\left[\mathrm{O}_{2}(3)\right] /\left[\mathrm{O}_{2}(3)\right]_{B}=0.48-$ $0.98,\left[\mathrm{O}_{2}(4)\right] /\left[\mathrm{O}_{2}(4)\right]_{B}=0.23-0.97,\left[\mathrm{O}_{2}(5)\right] /\left[\mathrm{O}_{2}(5)\right]_{B}=$ $0.09-0.97$.

Figures 8 and 9 display the measured (crosses) and calculated (lines) NmF2 (bottom panel), hmF2 (middle panel), and the electron temperature, $T_{e m}$, at the F2 peak altitude (top panel) above Millstone Hill for the magnetically quiet and disturbed period of 20-30 January, 1993. Solid lines represent the results obtained from the model with effects of $\mathrm{N}_{2}(v>0)$ and $\mathrm{O}_{2}(v>0)$ on the $\mathrm{O}^{+}\left({ }^{4} \mathrm{~S}\right)$ loss rate and the heating rate of electrons due to the de-excitation reactions of vibrationally excited $\mathrm{N}_{2}$ and $\mathrm{O}_{2}$ using the non-Boltzmann populations of the first five vibrational levels by solving the $\mathrm{N}_{2}(v=1-$ $5)$ and $\mathrm{O}_{2}(v=1-5)$ time-dependent continuity equations, and the $\mathrm{N}_{2}(v)$ and $\mathrm{O}_{2}(v)$ vibrational quanta equations as well as the additional plasmaspheric heating. Dotted lines represent the model results when $\mathrm{N}_{2}(v>0)$ and $\mathrm{O}_{2}(v>0)$ are not included in the calculations of $L$. Dashed lines give the model results when $\mathrm{N}_{2}(v>0)$ is included and $\mathrm{O}_{2}(v>0)$ is not included in calculations of $L$. The figures are divided into two parts to avoid a compressed time scale.

As Figs. 8 and 9 show, there is a large increase in the modelled NmF2 without the vibrationally excited nitrogen and oxygen molecules. Neither the daytime and nor night-time densities are reproduced by the model without $\mathrm{N}_{2}(v>0)$ and $\mathrm{O}_{2}(v>0)$ in the loss rate of $\mathrm{O}^{+}\left({ }^{4} \mathrm{~S}\right)$ ions, and inclusion of vibrationally excited $\mathrm{N}_{2}$ and $\mathrm{O}_{2}$ in

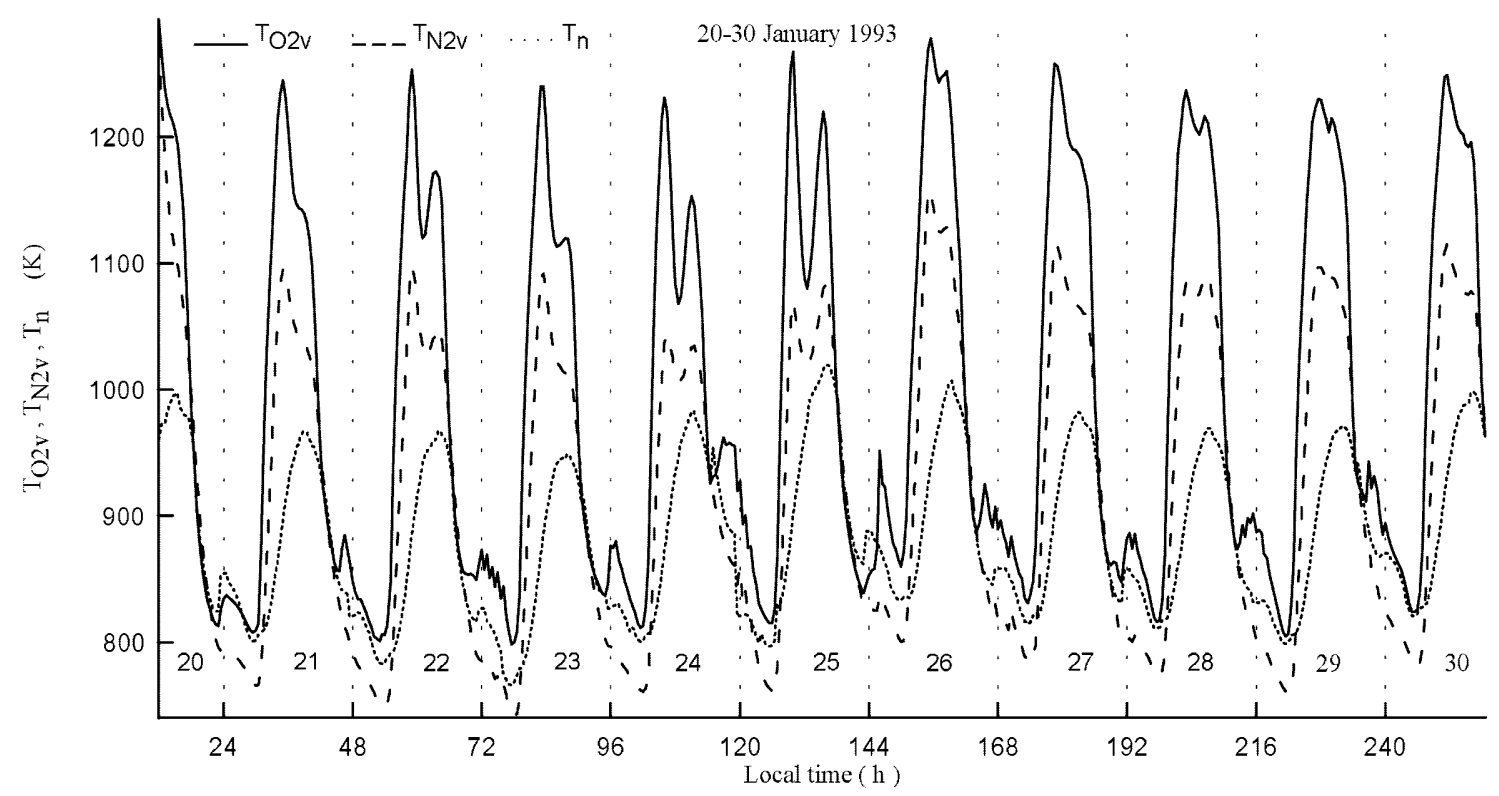

Fig. 7. The time variations of the vibrational temperatures of $\mathrm{O}_{2}$ (solid line) and $\mathrm{N}_{2}$ (dashed line), and the neutral temperature (dotted line) during the 20-30 January, 1993, period at the F2 peak altitude above Millstone Hill. The model of the ionosphere and plasmasphere includes the additional heating rate of the electron gas in the plasmasphere shown by solid lines in top panels of Figs. 5 and 6 , and the new approach of Eqs. (9) and (10) with the value of $C=20$ for the electron heat flux along a magnetic field line 


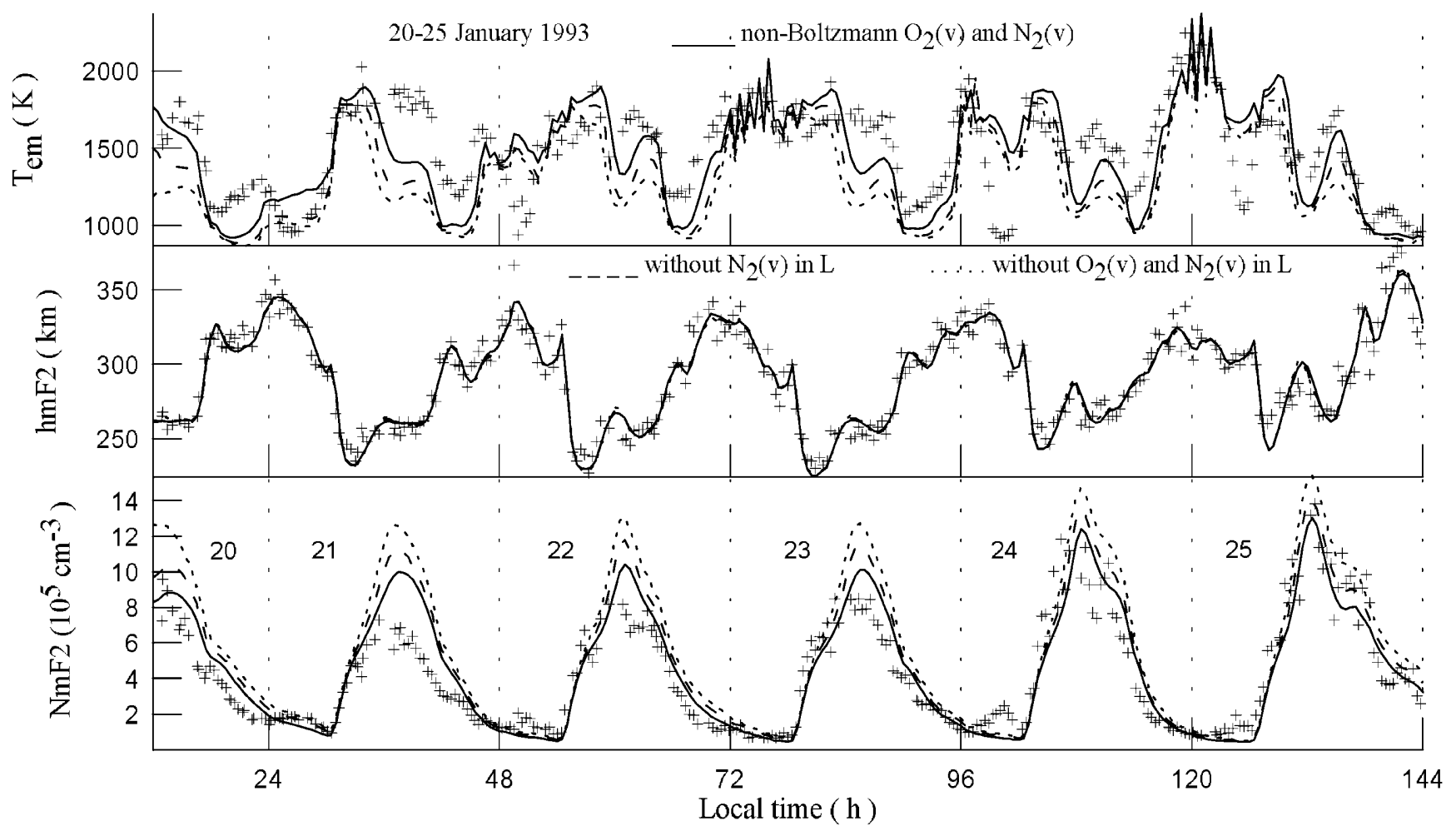

Fig. 8. Observed (crosses) and calculated (lines) NmF2 (bottom panel), hmF2 (middle panel), and the electron temperature, $T_{e m}$, at the F2 peak altitude (top panel) above Millstone Hill for the magnetically quiet and disturbed period 20-25 January, 1993. Solid lines show the modelled results obtained with effects of $\mathrm{N}_{2}(v>0)$ and $\mathrm{O}_{2}(v>0)$ on the $\mathrm{O}^{+}\left({ }^{4} \mathrm{~S}\right)$ loss rate, $L$, (see Eq. 3) using the nonBoltzmann populations of the first five vibrational levels of $\mathrm{N}_{2}(v)$ and $\mathrm{O}_{2}(v)$. Dotted lines represent the model results when $\mathrm{N}_{2}(v>0)$ and
$\mathrm{O}_{2}(v>0)$ were not included in the calculations of L. Dashed lines give the model results without effects of $\mathrm{N}_{2}(v>0)$ on $L$ when $\mathrm{O}_{2}(v>0)$ was included in the calculations of $L$. The model of the ionosphere and plasmasphere includes the additional heating rate of the electron gas in the plasmasphere shown by solid lines in top panels of Figs. 5 and 6, and the new approach of Eqs. (9) and (10) with the value of $C=20$ for the electron heat flux along magnetic field line

daytime electron temperature up to about $580 \mathrm{~K}$. The effects of vibrationally excited $\mathrm{O}_{2}$ and $\mathrm{N}_{2}$ on $N_{e}$ are most pronounced during daytime.

It should be noted that the modelled electron temperature is very sensitive to the electron density, and, as a result, there is a large decrease in the modelled electron temperatures without the vibrational excited nitrogen and oxygen in the ionosphere-plasmasphere model (see upper panels of Figs. 8 and 9). Inclusion of vibrationally excited $\mathrm{N}_{2}$ and $\mathrm{O}_{2}$ in the loss rate of $\mathrm{O}^{+}\left({ }^{4} \mathrm{~S}\right)$ ions which brings the measured and modelled electron densities into better agreement also tends to give close agreement between measured and modelled electron temperatures.

Figures 8 and 9 show that the modelled electron densities and temperatures are in a reasonable accord with the observed values if the non-Boltzmann vibrational $\mathrm{N}_{2}$ and $\mathrm{O}_{2}$ distribution assumptions are used. However, the model results with the vibrational states of $\mathrm{N}_{2}(v)$ and $\mathrm{O}_{2}(v)$ included does not always fit the data. There is a close relationship between electron temperature and electron density, and it is not possible to determine whether the increase in density results from a lowering of the electron temperature or vise versa, since both phenomena are coupled. Figures 8 and 9 show that when the model accurately reproduces the electron

$$
\text { comparison between solid and dotted lines at top panel }
$$
of Figs. 8 and 9) is the decrease of the calculated 


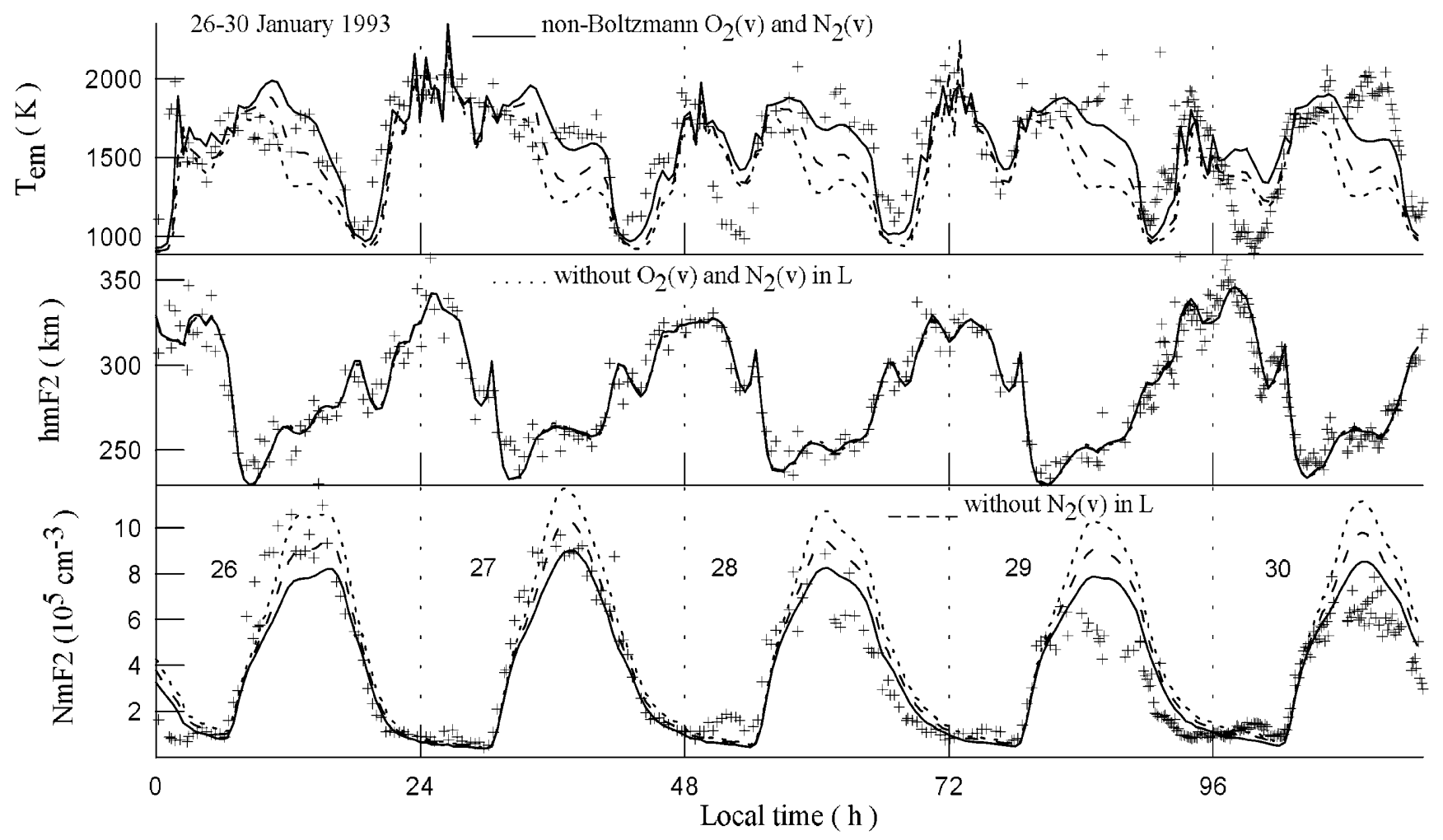

Fig. 9. Observed (crosses) and calculated (lines) NmF2 (bottom panel), hmF2 (middle panel), and the electron temperature, $T_{e m}$, at the F2 peak altitude (top panel) above Millstone Hill for the

density, it also reproduces the observed electron temperature with some small errors. The modelled electron temperature falls below the measured electron temperature during the time when the modelled electron density increases above the measured electron density. These discrepancies are probably due to the uncertainties in the model inputs, such as a possible inability of the MSIS-86 model to accurately predict the thermospheric response to this storm above Millstone Hill, and uncertainties in EUV fluxes, rate coefficients, and the flow of ionisation between the ionosphere and plasmasphere, and possible horizontal divergence of the flux of ionization above the station.

The relative magnitudes of the cooling rates are of particular interest to understand the main processes that determine the electron temperature. We found that the energy exchange between electrons and ions, and the electron cooling rates by vibrational excitation of $\mathrm{N}_{2}$ and $\mathrm{O}_{2}$ are the dominant cooling channels above $180 \mathrm{~km}$ during daytime. We found also that the contribution of the cooling of electrons by low-lying electronic excitation of $\mathrm{O}_{2}\left(a^{1} \Delta_{g}\right)$ and $\mathrm{O}_{2}\left(b^{1} \Sigma_{g}{ }^{+}\right)$, by excitation of $\mathrm{O}$ to the ${ }^{1} \mathrm{D}$ state, and by rotational excitation of $\mathrm{O}_{2}$ can be neglected above $160 \mathrm{~km}$ altitude since it represents not more than a few percent of the total cooling rate during the quiet and geomagnetic storm period 20-30 January, 1993. The atomic oxygen fine structure cooling rate of thermal electrons is not the dominant electron cooling process in agreement with the conclusions of Pavlov and Berrington (1999). magnetically quiet and disturbed period 26-30 January, 1993. The curves are the same as in Fig. 8

\section{Conclusions}

The Millstone Hill incoherent-scatter radar and the EXOS-D satellite measurements, and the IZMIRAN ionosphere-plasmasphere model simulations of electron density and temperature for the geomagnetically quiet and disturbed period of 20-30 January, 1993, were used to study the thermal electron energy budget of the ionosphere and plasmasphere, the effects of $\mathrm{N}_{2}(v)$ and $\mathrm{O}_{2}(v)$ on the electron density and temperature at moderate solar-activity conditions, and to evaluate the current capabilities of the IZMIRAN model. The model used is an enhanced and updated version of the IZMIRAN model that we have steadily developed over the years. The updated model uses the revised electron cooling rates by vibrational and rotational excitation of $\mathrm{O}_{2}$ and $\mathrm{N}_{2}$, and by electron impact excitation of fine structure levels of atomic oxygen given by Pavlov (1998a, c) and Pavlov and Berrington (1999) in calculations of the electron temperature, and the updated elastic and inelastic cross sections of the neutral components of the atmosphere to solve the Boltzmann equation for photoelectron fluxes.

We have examined the thermal electron energy budget of the mid-latitude ionosphere and plasmasphere. Our initial comparison between the measured and modelled electron temperatures show that the modelled electron temperatures are much less then the electron temperatures measured by the instruments on board of the EXOS-D satellite in the plasmasphere if the 
ionosphere-plasmasphere model without an additional heating of electrons is used. The heating provided by trapped photoelectrons cannot account for the observed high electron temperatures in the plasmasphere. We have evaluated the value of the additional heating rate that should be added to the normal photoelectron heating in the electron energy equation in the daytime plasmasphere region above $5000 \mathrm{~km}$ along the magnetic field line to explain the high electron temperature between 15:22:39 UT and 15:26:39 UT on 22 January and from 14:32:14 UT to 14:39:02 UT on 24 January measured by the instruments on the EXOS-D satellite board into the Millstone Hill magnetic field flux tube in the Northern Hemisphere. The additional heating brings the measured and modelled electron temperatures into agreement in the plasmasphere and into very large disagreement in the ionosphere if the classical electron heat flux along magnetic field line is used.

A new approach is presented to model the electron temperature in the ionosphere and plasmasphere. A new effective electron thermal conductivity coefficient along the magnetic field line is derived from the flux-limited model to make the measured and modelled electron temperature agree. The ratio of the effective electron thermal conductivity coefficient to the classical electron thermal conductivity coefficient of Spitzer and Harm (1953) is a function of $T_{e},\left|(\partial / \partial s) T_{e}\right|, N_{e}$, and the fitting flux-limited theory parameter which value is estimated to be between 10 and 30 from the comparison of the measured and modelled electron temperature in the plasmasphere. The calculations show that the good agreement between the modelled and measured electron temperatures is achieved by using the middle value of $C=20$. This new approach leads to a heat flux which is less than that given by the Spitzer-Harm theory. The reason for the low thermal conductivity of electrons in the topside ionosphere and in the most part of the plasmasphere where the value of $\lambda / L_{p}$ is larger than $10^{-2}$ is the deviation of the electron distribution from the Maxwellian distribution. The heat flux in this region is carried not only by thermal electrons but also by a number of superthermal electrons whose mean free path is much larger than the thermal electron mean free path. The electron temperatures observed by the instruments on board of the EXOS-D satellite in the plasmasphere are explained by the additional heating of electrons in the plasmasphere and the decrease of the thermal conductivity in the topside ionosphere and the most part of the plasmasphere found for the first time in this study. We found also that the effects of the daytime additional plasmaspheric heating of electrons on the electron temperature and density are small at the F-region altitudes if the electron heat flux modification is used.

In order to reproduce the high night-time observed electron temperatures at the F2 peak altitude, an additional plasmaspheric heating rate of electrons is required, and a new algorithm is presented to determine the amount of this plasmaspheric heating. It was found that the additional plasmaspheric heating greatly improves the model results at night producing a model electron temperature that is much closer to the measured electron temperature than in the standard case without this heating. Our results show that there are a number of peaks in additional heating time behavior at night, and the value of $Q_{\text {night }}$ is less than $Q_{\text {day }}$. We found that the effect of the calculated night-time additional heating on NmF2 can be considered negligible.

The deviations from the Boltzmann distribution for the first five vibrational levels of $\mathrm{N}_{2}$ and $\mathrm{O}_{2}$ were calculated. The present study suggests that the deviations from the Boltzmann distribution are not significant at the first vibrational levels of $\mathrm{N}_{2}$ and $\mathrm{O}_{2}$ and the second level of $\mathrm{O}_{2}$, and the calculated distributions of $\mathrm{N}_{2}(v)$ and $\mathrm{O}_{2}(v)$ are highly non-Boltzmann at vibrational levels $v>2$. The calculations also showed that the $\mathrm{O}_{2}$ and $\mathrm{N}_{2}$ vibrational temperatures during the quiet periods are less than during the magnetic storm periods. During daytime the high vibrational temperatures stem from the enhanced thermal excitation of $\mathrm{O}_{2}$ and $\mathrm{N}_{2}$ as a result of high thermal electron temperatures at F2region altitudes.

We found that the resulting effect of $\mathrm{N}_{2}(v>0)$ and $\mathrm{O}_{2}(v>0)$ on the $\mathrm{NmF} 2$ is the decrease of the calculated daytime $\mathrm{NmF} 2$ up to a factor of 1.5 for the nonBoltzmann $\mathrm{N}_{2}(v)$ and $\mathrm{O}_{2}(v)$ vibrational distribution assumptions. The modelled electron temperature is very sensitive to the electron density, and this decrease in electron density results in the increase of the calculated daytime electron temperature up to about $580 \mathrm{~K}$ at the F2 peak altitude. Both the daytime and night-time densities are not reproduced by the model without $\mathrm{N}_{2}(v>0)$ and $\mathrm{O}_{2}(v>0)$, and inclusion of vibrationally excited $\mathrm{N}_{2}$ and $\mathrm{O}_{2}$ brings the model and data into better agreement. The effects of vibrationally excited $\mathrm{O}_{2}$ and $\mathrm{N}_{2}$ on the electron density and temperature are most pronounced during daytime.

Acknowledgements. This work was carried out while A.V. Pavlov was visiting ISAS (Japan). He acknowledges the warm hospitality of ISAS. The authors wish to thank M.J. Buonsanto (he passed away suddenly and untimely on 20 October 1999 of a heart attack), J.C. Foster, and other personnel at Millstone Hill Observatory of the Massachusetts Institute of Technology for providing CEDAR Database data. We would like to thank anonymous referees for critical reading of the manuscript as reviewers and for helpful comments.

Topical Editor M. Lester thanks B. Emery and M. Förster for their help in evaluating this paper.

\section{References}

Abe, T., K.-I. Oyama, H. Amemiya, S. Watanabe, T. Okuzawa, and K. Schlegel, Measurement of temperature and velocity distribution of thermal electrons by the Akebono (EXOS-D) satellite, J. Geomagn. Geoelectr., 42, 537-554, 1990.

Abe, T., K.-I. Oyama, S. Watanabe, and H. Fukunishi, Characteristic features of electron temperature and density variations in the field-aligned current region, J. Geophys. Res., 98, $11257-$ $11266,1993$.

Albritton, D. L., I. Dotan, W. Lindinger, M. McFarland, J. Tellinghuisen, and F. C. Fehsenfeld, Effects of ion speed distributions in flow-drift tube studies on ion -neutral reactions, J. Chem. Phys., 66, 410-421, 1977. 
Albritton, J. R., E. A. Williams, I. B. Bernstein, and K. P. Swartz, Non local electron heat transport by not quite MaxwellBoltzmann distributions, Phys. Rev. Lett., 57, 1887-1890, 1986.

Balan, N., K.-I. Oyama, G. J. Bailey, and T. Abe, Plasmaspheric electron temperature studies using satellite observations and a theoretical model, J. Geophys. Res., 101, 15 323-15 330, 1996 a.

Balan, N., K.-I. Oyama, G. J. Bailey, and T. Abe, Plasmaspheric electron temperature profiles and the effects of photoelectron trapping and an equatorial high-altitude heat source, J. Geophys. Res., 101, 21 689-21 696, 1996b.

Bell, A. R., R. G. Evans, and D. J. Nicholas, Electron energy transport in steep temperature gradients in laser-produced plasmas, Phys. Rev. Lett., 46, 243-246, 1981.

Buonsanto, M. Codrescu, B. A. Emery, C. G. Fesen, T. J. FullerRowell, D. J. Melendez-Alvira, and D. P. Sipler, Comparison of models and measurements at Millstone Hill during the January 24-26, 1993, minor storm interval, J. Geophys. Res., 102, 72677277, 1997.

Choi, S. H., and H. E. Wilhelm, Similarity transformation for explosions in two-component plasmas with thermal energy and heat-flux relaxation, Phys. Rev. A, 14, 1825-1834, 1976.

Clark, D. H., W. J. Raitt, and A. P. Willmore, Temperature anisotropies in the terrestrial ionosphere and plasmasphere, J. Atmo. Terr. Phys., 35, 63-76, 1973.

Clause, P. J., and R. Balescu, A non-linear approach to the kinetic theory of heat conductivity in a plasma, Plasma Phys., 24, 14291448, 1982.

Cowie, L. L., and C. F. Mckee, The evaporation of spherical clouds in a hot gas. I. Classical and saturated mass loss rates, Astrophys. J., 211, 135-146, 1977.

Cravens, P. D., R. H. Comfort, P. G. Richards, and J. M. Grebowsky, Comparison of modelled $\mathrm{N}^{+}, \mathrm{O}^{+}, \mathrm{H}^{+}$, and $\mathrm{He}^{+}$in the midlatitude ionosphere with mean densities and temperatures from Atmosphere Explorer, J. Geophys. Res., 100, 257268, 1995.

Denmark, H. G., and R. W. Schunk, Temperature anisotropies in the terrestrial ionosphere and plasmasphere, Rev. Geophys., 25, 1659-1679, 1987.

Denton, M. N., G. J. Bailey, Y. Z. Su, K.-I. Oyama, and T. Abe, High altitude observations of electron temperature and possible north-south asymmetry, J. Atmos. Sol. Terr. Phys., 61, 775-788, 1999.

Evans, J. V., Midlatitude F-region densities and temperatures at sunsport minimum, Planet. Space Sci., 15, 1387-1405, 1967.

Fechner, W. B., and F. J. Mayer, Analysis of flux-relaxed electron heat waves, Phys. Fluids, 27, 1538-1544, 1984.

Ferguson, E. E., N. G. Adams, D. Smith, and E. Alge, Rate coefficients at $300 \mathrm{~K}$ for the vibrational energy transfer reactions from $\mathrm{N}_{2}(v=1)$ to $\mathrm{O}_{2}{ }^{+}(v=0)$ and $\mathrm{NO}^{+}(v=0)$, J. Chem. Phys., 80, 6095-6098, 1984.

Fesen, C. G., B. A. Emery, M. Buonsanto, Q. H. Zhou, and M. P. Sulzer, Simulations of the F-region during the January 1993 10day campaign, J. Geophys. Res., 102, 7249-7265, 1997.

Fontheim, E. G., R. S. B. Ong, R. G. Roble, H. G. Mayr, M. J. Baron, W. H. Hoegy, V. B. Wickwar, R. R. Vondrak, and J. A. Jonson, Effect of anomalous transport coefficients on the thermal structure of the storm time auroral ionosphere, J. Geophys. Res., 83, 4831-4836, 1978.

Forbes, J. M., D. Revelle, X. Zhang, and R. E. Markin, Longitude structure of the ionosphere $\mathrm{F}$ region from TOPEX/Poseidon and ground-based data during January 20-30, 1993, including the quasi 2-day oscillations, J. Geophys. Res., 102, 7293-7299, 1997.

Garner, T. W., P. G. Richards, and R. H. Comfort, Anomalous nightime electron temperature events over Millstone Hill, J. Geophys. Res., 99, 11411-11416, 1994.

Gary, S. P., A. G. Sgro, and A. W. DeSilva, Effects of an axial heat flux limit in linear theta pinches, Phys. Fluids, 21, 2103-2107, 1978.

Gray, D. R., and J. D. Kilkenny, The measurement of ion acoustic turbulence and reduced thermal conductivity caused by a laser temperature gradient in a laser heated plasma, Plasma Phys., 22, 81-111, 1980.

Hedin, A. E., MSIS-86 thermospheric model, J. Geophys. Res., 92, 4649-4662, 1987.

Hierl, M. P., I. Dotan, J. V. Seeley, J. M. Van Doren, R. A. Morris, and A. A. Viggiano, Rate constants for the reactions of $\mathrm{O}^{+}$with $\mathrm{N}_{2}$ and $\mathrm{O}_{2}$ as a function of temperature (300-1800 K), J. Chem. Phys., 106, 3540-3544, 1997.

Horwitz, J. L., R. H. Comfort, P. G. Richards, M. O. Chandler, C. R. Chappel, P. Anderson, W. B. Hanson, L. H. Brace, Plasmasphere-ionosphere coupling. 2. Ion composition measurements at plasmaspheric and ionospheric altitudes and comparison with modeling results. J. Geophys. Res., 95, 7949-7959, 1990.

Itikawa, Y., Electron collisions with $\mathrm{N}_{2}, \mathrm{O}_{2}$, and $\mathrm{O}$ : what we do and do not know, in Advances in atomic, molecular, and optical physics, 33, 253-273, 1994, New York, Academic Press.

Jonson, J. A., R. S. B. Ong, and E. G. Fontheim, Turbulent transport and heating in the auroral plasma of the topside ionosphere, Planet. Space Sci., 27, 203-210, 1979.

Joshipura, K. N., and P. M. Patel, Cross sections of $\mathrm{e}^{-}-\mathrm{O}$ scattering at intermediate and high energies $\left(\mathrm{E}_{\mathrm{i}}=8.7-1000 \mathrm{eV}\right)$, Phys. Rev., 48, 2464-2467, 1993.

Kanic, I., S. Trajmar, and J. C. Nickel, Total electron scattering and electronic state excitations cross sections for $\mathrm{O}_{2}, \mathrm{CO}_{2}$, and $\mathrm{CH}_{4}$, J. Geophys. Res., 98 E, 7447-7460, 1993.

Khan, S. A., and T. D. Rognlien, Electron energy transport in steep temperature gradients in laser-produced plasmas, Phys. Fluids, 24, 1442-1446, 1981.

Khazanov, G. V., T. E. More, J. L. Horwitz, P. G. Richards, and Y. V. Konikov, Effect of anizotropic thermal conductivity on the temperature structure of the ionosphere-plasmasphere system, J. Geophys. Res., 101, 13 399-13 406, 1996.

Krinberg, I. A. and G. K. Matafonov, Coulomb collision-induced photoelectron trapping by the geomagnetic field and electron gason the heating in the plasmasphere, Anal. Geophysi., 34, 89-96, 1978.

Krinberg, I. A. and A. V. Tachilin, Ionosphere and plasmasphere (in Russian), Nauka, Moscow, 1984.

Lee, Y. T., and R. M. More, An electron conductivity model for dense plasmas, Phys. Fluids, 27, 1273-1286, 1984.

Majeed, T., and D. J. Strickland, New survey of electron impact cross sections for photoelectron and auroral electron energy loss calculations, J. Phys. Chem. Ref. Data, 26, 335-349, 1997.

Malone, R. C., R. L. McCrory, and R. L. Morse, Indications of strongly flux-limited electron thermal conduction in laser-target experiments, Phys. Rev. Lett., 34, 721-724, 1975.

Mason, R. J., Apparent and real thermal inhibition in laserproduced plasmas, Phys. Rev. Lett., 47, 652-656, 1981.

Matte, J. P., and J. Virmont, Electron heat transport down steep temperature gradients, Phys. Rev. Lett., 49, 1936-1939, 1982.

McFarland, M., D. L. Albritton, F. C. Fehsenfeld, E. E. Ferguson, and A. L. Schmeltekopf, Flow-drift technique for ion mobility and ion-molecule reaction rate constant measurements, II. Positive ion reaction of $\mathrm{N}^{+}, \mathrm{O}^{+}$, and $\mathrm{N}_{2}^{+}$with $\mathrm{O}_{2}$ and $\mathrm{O}^{+}$ with $\mathrm{N}_{2}$ from thermal to $2 \mathrm{eV}, J$. Chem. Phys., 59, 6620-6628, 1973.

Oyama, K.-I., and K. Schlegel, Observations of electron temperature anisotropy in the ionosphere: a review, Ann. Geophysicae, 6, 389-401, 1988.

Pavlov, A. V., The role of vibrationally excited nitrogen in the formation of the mid-latitude negative ionospheric storms, Ann. Geophysicae, 12, 554-564, 1994.

Pavlov, A. V., Mechanisms of the electron density depletion in the SAR arc region, Ann. Geophysicae, 14, 211-221, 1996.

Pavlov, A. V., Subauroral red arcs as a conjugate phenomenon: comparison of OV1-10 satellite data with numerical calculations, Ann. Geophysicae, 15, 984-998 1997.

Pavlov, A. V., New electron energy transfer rates for vibrational excitation of $\mathrm{N}_{2}$, Ann. Geophysicae, 16, 176-182, 1998a.

Pavlov, A. V., The role of vibrationally excited oxygen and nitrogen in the ionosphere during the undisturbed and geomagnetic 
storm period of 6-12 April 1990, Ann. Geophysicae, 16, 589601, 1998b.

Pavlov, A. V., New electron energy transfer and cooling rates by excitation of $\mathrm{O}_{2}$, Ann. Geophysicae, 16, 1007-1013, 1998c.

Pavlov, A. V., and M. J. Buonsanto, Comparison of model electron densities and temperatures with Millstone Hill observations during undisturbed periods and the geomagnetic storms of March 16-23 and April 6-12, 1990, Ann. Geophysicae, 15, 327344, 1997.

Pavlov, A. V., and K. A. Berrington, Cooling rate of thermal electrons by electron impact excitation of fine structure levels of atomic oxygen, Ann. Geophysicae, 17, 919-924, 1999.

Pavlov, A. V., M. J.Buonsanto, A. C. Schlesier, and P. G. Richards, Comparison of models and data at Millstone Hill during the June 5-11, 1991 storm, J. Atmos. Solar-Terrestrial Phys, 61, 263-279, 1999.

Peterson, J. R., A. Le Padellec, H. Danared, G. H. Dunn, M. Larsson, A. Larson, R. Peverall, C. Stromholm, S. Rosen, M. Ugglas, W. J. Van der Zande, Dissociative recombination and excitation of $\mathrm{N}_{2}^{+}$: cross sections and product branching ratios, J. Chem. Phys., 108, $1978-1988,1998$.

Radzig, A. A., and B. V. Smirnov, The reference book in atomic and molecular physics (in Russian), Atomizdat, Moscow, 1980.

Richards, P. G., An improved algorithm for determining neutral winds from the height of the F2 peak electron density, J. Geophys. Res., 96, 17839-17846,1991.

Richards, P. G., and D. G. Torr, Ratios of photoelectron to EUV ionization rates for aeronomic studies, J. Geophys. Res., 93, 4060-4066, 1988.

Richards, P. G., and G. W. Khazanov, On the thermal electron energy balance in the ionosphere in January 1993 and June 1990, J. Geophys. Res., 102, 7369-7377, 1997.
Richards, P. G., D. G. Torr, and W. A. Abdou, Effects of vibrational enhancement of $\mathrm{N}_{2}$ on the cooling rate of ionospheric thermal electrons, J. Geophys. Res., 91, 304-310, 1986.

Robertson, A. G., M. T. Elford, R. W. Crompton, M. A. Morrison, W. Sun, and W. K. Trail, Rotational and vibrational excitation of nitrogen by electron impact, Aust. J. Phys., 50, 441-472, 1997.

Scali, J. L., B. W. Reinish, P. G. Richards, Q. Zhou, M. Sulzer, and W. E. Swartz, Comparison of incoherent scatter radar and digisonde measurements with field line interhemispheric plasma modelled results at middle and low latitudes, J. Geophys. Res., 102, 7345-7355, 1997.

Schmeltekopf, A. L., E. E. Ferguson, and F. C. Fehsenfeld, Afterglow studies of the reactions $\mathrm{He}^{+}, \mathrm{He}\left(2^{3} \mathrm{~S}\right)$, and $\mathrm{O}^{+}$with vibrationally excited $\mathrm{N}_{2}$, J. Chem. Phys., 48, 2966-2973, 1968.

Schulz, G. J., A review of vibrational excitation of molecules by electron impact at low energies, in Principles of laser plasmas, 33-76, Ed. G. Berkefi, Interscience, New York, 1976.

Spitzer, L., and R. Harm, Transport phenomena in a completely ionized gas, Phys. Rev., 89, 977-981, 1953.

St.-Maurice, J.-P. and D. G. Torr, Nonthermal rate coefficients in the ionosphere: The reactions of $\mathrm{O}^{+}$with $\mathrm{N}_{2}, \mathrm{O}_{2}$ and $\mathrm{NO}$, J. Geophys. Res., 83, 969-977, 1978.

Tobiska, W. K., and F. G. Eparvier, EUV97: Improvements to EUV irradiance modeling in the soft X-rays and FUV, Solar Phys., 177, 147-159, 1998.

Titheridge, J. E., Model results for the ionospheric E region: solar and seasonal changes, Ann. Geophysicae., 15, 63-78, 1997.

Williams, J. F., and L. J. Allen, Low-energy elastic scattering of electrons from atomic oxygen, J. Phys. B: At. Mol. Opt. Phys., 22, 3529-3539, 1989.

Zawaideh, E. and N. S. Kim, Analysis of flux-relaxed electron heat waves, Phys. Fluids, 31, 3280-3285, 1988. 